6

\title{
Vérification des généalogies (tạ̣qīq al-ansāb) et centralité égyptienne
}

\author{
Le Syndicat des descendants du Prophète (niqābat al-ashrāf) à l'époque \\ contemporaine
}

\author{
Catherine Mayeur-Jaouen
}

Au Caire, près de la mosquée al-Azhar et du mausolée d'al-Husayn, petit-fils du Prophète, au bord de la voie rapide Șalāḥ Sālim et face aux mausolées de la Cité des morts, se dresse un ensemble harmonieux de trois bâtiments modernes construits dans le style néo-mamelouk ${ }^{1}$. Cet ensemble construit au début des années 2000 incarne de façon démonstrative l'islam d'État égyptien : il regroupe le siège central d'al-Azhar (mashyakhat al-Azhar), l'institution d'État chargée de la fatwa (dār al-iftầ) et le Syndicat des descendants du Prophète (niqābat al-ashrāf). Voilà une inégale trilogie: al-Azhar, nébuleuse d'enseignement islamique plus que millénaire, nationalisée en 1962, reste la grande université islamique, aujourd'hui en proie aux divisions internes et aux défis du salafisme ${ }^{2}$; le dār al-ifta ${ }^{2}$, création étatique en 1895 liée à la codification et à la rationalisation du droit musulman, continue à « définir l'islam pour l'État égyptien» selon l'heureuse expression de Skovgaard-Petersen, tout en étant concurrencée par d'innombrables instances et médias ${ }^{3}$; enfin le Syndicat des descendants du Prophète (niqābat al-ashrāf) est la réapparition récente, en 1991, d'une très ancienne institution.

1 Je remercie le naqüb al-Sayyid Maḥmūd al-Sharîf pour avoir bien voulu me laisser enquêter à la niqāba, le docteur Sulaymān, l'ustādh Aḥmad Yaḥyā et tous les membres du Comité de vérification des généalogies pour leur accueil, leur patience et leur gentillesse. Je remercie vivement pour son aide précieuse Aḥmad Maḥmūd Mușțafā.

2 Sur al-Azhar au XIX ${ }^{\mathrm{e}}$ siècle, le livre de référence reste celui de Delanoue, Moralistes et politiques musulmans; à compléter pour la réforme de la fin du XIXe siècle par Raineau, "Des tableaux noirs à l'ombre du minbar" ; Raineau, "Mendiante et orgueilleuse ?"; et Falk Gesink, Islamic Reform and Conservatism. Sur al-Azhar au $\mathrm{xx}^{\mathrm{e}}$ siècle, synthèse pratique avec Luizard, "Al-Azhar, institution sunnite réformée". Voir également Botiveau, "L'université al-Azhar au gré du changement politique". Une importante bibliographie en arabe, récemment éditée par l'université d'al-Azhar elle-même, fait la part belle à la prosopographie : Khafājī et Șubḥ, al-Azharfíalf 'ām.

3 Skovgaard-Petersen, Defining Islam for the Egyptian State. 
Le terme «syndicat», traduction littérale de niqāba, ne doit pas prêter à confusion : il ne s'agit pas d'un syndicat professionnel, mais d'une association dont l'histoire récente s'ancre dans la construction de l'État égyptien à partir de Méhémet Ali (1805-48) et dont la tradition revendiquée remonte, par définition, au Prophète et aux débuts de l'islam. Pour être complet, il faudrait ajouter à cet ensemble tripartite deux autres institutions: le ministère des Waqfs, consacré à l'administration des fondations pieuses nationalisées sous Nasser (1956-70), dont le revenu finance mosquées, mausolées, fonctionnaires du religieux, ainsi que le Haut Conseil des confréries soufies (al-majlis al-alā li-l-țuruq al-șüfiyya), dont le siège, tout proche de la niqäba et de la mashyakhat al-Azhar, flanque le mausolée d'al-Ḥusayn. Si al-Azhar, et dans une moindre mesure le Haut Conseil des confréries et le dār al-iftà', ont fait l'objet de travaux de recherche, ce n'est pas le cas de la niqābat al-ashrāf égyptienne à l'époque contemporaine, ni en arabe, ni en langues occidentales. L'important livre de Frederick De Jong sur les institutions liées aux confréries soufies dans l'Égypte du XIX ${ }^{\mathrm{e}}$ siècle reste sans équivalent pour les $\mathrm{XX}^{\mathrm{e}}$ et $\mathrm{XXI}^{\mathrm{e}}$ siècles ${ }^{4}$.

Il est facile de négliger la niqābat al-ashrāf, cette institution discrète dont la grande majorité des Égyptiens ignorent jusqu'à l'existence, ou d'en faire une simple émanation de l'islam d'État égyptien depuis le début du XIX ${ }^{\mathbf{e}}$ siècle. La subtile autonomie de la niqāba et son activité principale, la vérification des généalogies, lui donnent pourtant un visage sui generis qui renvoie à l'implicite, aux liens tacites, à l'histoire locale, à la science de la généalogie ('ilm $a$-ansāb), à tout ce que représentent les liens d'un islam de familles en Égypte, encore fortement territorialisé. Mille dimensions sociales et religieuses font échapper la niqāba à l'univers bureaucratique et politique auquel elle appartient au prime abord. Comme les autres institutions citées, elle participe d'un islam égyptien qui défie la mondialisation et insiste (en les reformulant) sur les continuités menacées par les mutations trop rapides du présentisme. C'est finalement une interprétation de l'intercession prophétique qui constitue les ashräf en groupe privilégié. Cette prétention, aujourd'hui contestée par le salafisme, est ignorée par une majorité d'Égyptiens.

Après le récit d'une première visite à la niqā $b a$, j'étudierai la façon dont on raconte l'histoire de la niqāba en Égypte, en comparant le récit usuel - celui des historiens et celui que la niqāba donne à voir d'elle-même - avec celui du

4 Il n'y a pas eu d'études récentes du Haut-Conseil des confréries soufies depuis le livre fondamental de De Jong sur le XIX ${ }^{\mathbf{e}}$ siècle, Țuruq and Țuruq-linked Institutions, et les études plus ponctuelles de Luizard, "Le soufisme égyptien contemporain". Signalons une très bonne enquête de Paonessa sur les divisions au sein du Haut Conseil des confréries soufies, et sur les tentatives de créer des partis politiques soufis lors de la révolution de 2011 : "Le rôle des confréries soufies durant les élections législatives de 2011 en Égypte". 
naqūb actuel en personne. J'analyserai ensuite la refondation de la niqāba en 1991, avant d'examiner le fonctionnement de l'institution, une administration hiérarchique, liée à l'État, mais autonome. Enfin, je verrai de plus près ce qui est au cœur même de la niqāba : la vérification des généalogies, en finissant par une dernière visite à la niqāba.

\subsection{Première visite à la niqāba: Aḥmad à la recherche de ses origines}

Commençons par une première visite à la niqāba pour camper le fonctionnement de l'institution, la façon dont elle se présente aux Égyptiens, et ce que représente la quête du nasab. Jeune professeur de français à al-Azhar, Aḥmad est né en 1980. Il a d'abord fait des études religieuses dans le système azharien, avant de poursuivre ses études universitaires en littérature française à l'université al-Azhar. Il sait être un descendant du Prophète (sharîf) par sa mère, mais n'en a pas la preuve, c'est-à-dire qu'il n'en possède pas d'attestation écrite ${ }^{5}$. Pour obtenir son attestation de généalogie (shahādat nasab), Aḥmad doit nécessairement passer par la niqāba où il se rend pour la première fois le 14 septembre 2017. À l'entrée du bâtiment, le contrôle est des plus simples : Aḥmad présente un document d'identité, inscrit son nom sur un registre, précise le motif de la requête. Il monte ensuite directement par l'ascenseur au quatrième étage, pour arriver au cœur de la niqāba: le Comité de vérification des généalogies (lajnat tahqīq al-ansāb).

Il n'entre pas tout de suite dans la grande salle où se réunit le Comité: un employé installé à un petit bureau devant l'entrée exerce un filtrage discret mais réel. Pour patienter, un factotum oriente d'abord Ahmad vers une autre pièce, un autre bureau, où un fonctionnaire d'un certain âge le reçoit dans le décor classique d'une administration égyptienne : un vieux téléphone fixe qui ne sert plus (mais le fonctionnaire manie deux téléphones portables), une grande télévision, une photocopieuse, un ordinateur obsolète, pas de livres, mais des piles de papiers raisonnablement rangées, un cendrier et un Coran posé sur le disque dur de l'ordinateur. Un drapeau égyptien et une calligraphie proclamant que «La justice est la base du pouvoir» (al-'adl asās al-mulk) ornent les murs. La conversation pleine de tact des deux hommes s'apparente rapidement à du name-dropping, tandis qu'ils échangent des cigarettes en

5 De façon significative, shahāda veut dire aussi profession de foi, témoignage ou, plus récemment, diplôme. 
commentant la qualité de telle ou telle marque ${ }^{6}$. Apparaissent bientôt des noms de famille, des noms de lieux (tous deux sont originaires du Delta, l'un de Țūkh, l'autre de Quwaysna), une mémoire familiale que l'on compare: la famille maternelle d'Aḥmad, issue de Mahallat Minūf, près de Ṭanțā, s'appelle la famille Husayn ('äilat Husayn). Quant au fonctionnaire, il ne tarde pas à mentionner qu'il descend du syndic des descendants du Prophète (naqïb $a l$-ashrāf) de la province de Minūfiyya sous le roi Farouk. Après ce premier repérage prudent, les deux interlocuteurs s'autorisent à aller plus loin. Comme le fonctionnaire a au doigt une bague ornée d'une turquoise, comme celles que portent les soufis et les cheikhs de confréries, Ahmad mentionne l'appartenance de sa mère à la confrérie soufie Naqshbandiyya. Jusquà la mort du cheikh Ghūda, de Minyat al-Qamh, elle le suivait dans les principaux mouleds (fêtes patronales des saints) du Caire, notamment celui de la petite-fille du Prophète, Sayyida Zaynab ${ }^{7}$. Ayant ainsi présenté ses liens avec le monde du soufisme égyptien, Ahmad obtient immédiatement la réplique de son interlocuteur qui déclare appartenir à la confrérie Rifăciyya.

C'est au milieu de ces échanges d'informations, distillées avec tact, qu'Ahmad, ayant bu un thé et fumé sa cigarette, expose finalement son cas. Bien qu'il soit sharīf par sa mère, il ne possède pas d'attestation du Syndicat. Il sait cependant que ses cousins maternels disposent d'une généalogie attestée (l'expression est : awläd khāltī munassabūn) et d'un arbre généalogique (shajarat al-'ảila) qui a déjà été, par le passé, certifié par la niqāba. Le fonctionnaire est en mesure de le rassurer: le cas d'Ahmad est simple et il pourra obtenir rapidement la shahāda du moment qu'il se sera d'abord procuré une copie de l'arbre généalogique initial auprès de ses cousins. Une simple photographie pourrait même suffire. Muni de cette preuve essentielle et de documents complémentaires (son certificat de naissance, sa carte d'identité, ce qui permet d'établir le lien avec lesdits cousins), il ne restera plus à Aḥmad qu'à ouvrir un dossier (malaff) au Comité de vérification des généalogies. La procédure va toutefois prendre un certain temps, puisqu'il faut que plusieurs membres du Comité, dont le directeur lui-même, contrôlent le dossier, et que tous donnent leur approbation au dossier, avant que ne soit produit le précieux certificat signé par le naqīb lui-même. Quand Aḥmad aura la certification désirée, il pourra finalement payer les frais de dossier et d'inscription à la niqāba, et

6 Cette liberté de fumer est un indice: fumer est réputé harām dans l'Égypte du début du $\mathrm{XXI}^{\mathrm{e}}$ siècle, à la suite de fatwas salafistes. La tabagie ordinaire des Égyptiens a donc considérablement régressé, et fumer est presque une prise de position. Deux ans plus tard, en 2019, l'interdiction de fumer est désormais partout affichée dans la niqāba.

7 Sur le culte de Sayyida Zaynab à l'époque contemporaine, cf. Abu-Zahra, The Pure and Powerful. 
obtenir la shahädat nasab, un document calligraphié qu'il mettra sous verre, comme le font généralement les ashräf dont la généalogie est reconnue par le Syndicat, et suspendra au mur dans un cadre. Il obtiendra aussi la carte de membre (bițāqa) de la niqāba, dont il faudra renouveler chaque année l'abonnement. Il peut aussi acquérir un badge, plutôt une sorte de pin (1o livres en janvier 2018), où le centre, de couleur verte, porte l'inscription Muhammad rasūl Allāh, entouré par une autre inscription (Niqābat al-sāda al-ashrāf Jumhüriyyat Mișr al-'arabiyya) : certains membres du Comité portent ce badge à la boutonnière de leur veston 8 .

Obtenir l'attestation de généalogie du Syndicat des descendants du Prophète, c'est prouver ce que l'on est, dans une procédure administrative codifiée où se jouent bien d'autres jeux d'appartenance ${ }^{9}$. La première visite d'Aḥmad aura discrètement exposé, en quelques minutes, les liens qui se tissent autour de la niqāba et des descendants du Prophète dans l'Égypte contemporaine : familles, racines locales, confréries soufies, administration bureaucratique, une histoire qui ne tient aucun compte des ruptures et des allégeances politiques, et propose au contraire de renouer de profondes continuités. Renvoyé à sa famille pour les démarches ultérieures, Aḥmad se rend dans le Delta chez ses parents : la conversation familiale prouve que son père aussi est sharîf, Ahmmad l'ignorait. Voilà un fait intéressant : du sharaf qui représente quelque chose d'important pour la famille maternelle d'Ahmmad, peut-être à cause de ses liens avec le soufisme et de la dévotion pour les ahl al-bayt, les Gens de la Maison du Prophète, son père ne fait que peu de cas. Comme des millions d'Égyptiens: parmi les 8 à 10 millions (les estimations données par les membres du Comité varient beaucoup) de descendants supposés du Prophète en Égypte, seuls 80,000 à 100,000 (mêmes oscillations) ont entrepris des démarches administratives pour demander et obtenir la shahāda auprès de la niqāba: seulement un pour cent des présumés descendants du Prophète sont dûment enregistrés à la niqā $b a$, et y font enregistrer leurs enfants. Mon enquête vérifiera assez constamment cette vérité : être descendant du Prophète en Égypte, et plus exactement être reconnu comme tel, n'est pas seulement un statut, une qualité ou une identité, mais un engagement qui vient croiser et corroborer d'autres engagements et d'autres identités. Le sharaf est une responsabilité. Aḥmad, qui en est conscient, préférera finalement ne pas établir le fameux certificat et

8 Notons que le terme $a$-sāda (pluriel de sayyid) est en Égypte rigoureusement synonyme d'ashrāf. Même remarque chez Winter, "The Ashrāf and Niqābat al-Ashrāf".

9 Grangaud et Michel, eds, L'identification; Oualdi et Amara, eds, La nationalité dans le monde arabe des années 1830 aux années 1960; Jungen et Raymond, eds, Pratiques d'archives; et Jungen, ed., L'ethnologue et les archives. 
la fameuse carte: mais il aura appris quelque chose sur son identité et sur son histoire familiale.

\subsection{Petite histoire de la niqābat al-ashrāf en Égypte : récits}

Telle qu'elle est généralement résumée par les journalistes ou les historiens, l'histoire institutionnelle de la niqāba décrit d'abord le lointain passé d'une institution de l'islam médiéval et ottoman, résumée dans deux articles - aussi remarquables qu'isolés - de Michael Winter ${ }^{10}$. Du passé médiéval, l'histoire de la niqāba saute directement au début du XIX ${ }^{\mathrm{e}}$ siècle, lorsque la niqāba devient une institution de l'État égyptien construit par Méhémet Ali. Et pourtant, malgré les rappels médiévaux et le poids du XIX ${ }^{\mathrm{e}}$ siècle, c'est l'importance de l'époque ottomane qui ressort des enquêtes généalogiques menées par la niqāba, comme de l'histoire des grandes familles d'ashrāf de l'Égypte contemporaine. Il est significatif que certaines des sources volontiers citées et utilisées par les généalogistes du Comité datent de l'époque ottomane, comme les recueils biographiques du Syrien al-Murādī (m. 1206/1791), notamment son Silk al-durar fì akhbār al-qarn al-thānī 'ashar, comme l'œuvre de Murtaḍa al-Zabīdī (m. 1206/1791), comme la chronique de l'historien al-Jabartī (m. 1825). Significatif encore que l'actuel directeur du Comité de vérification des ansāb, nommé en 2008, le docteur Sulaymān, professeur à l'université de Kafr al-Shaykh, soit justement un historien ottomaniste et l'auteur d'une monographie sur la niqābat al-ashrāf à l'époque ottomane.

Cette importance des ashräf à l'époque ottomane n'est donc pas occultée dans le travail de la niqāba, mais la vulgate préfère insister, une fois passé le nécessaire rappel médiéval, sur le XIX ${ }^{\mathrm{e}}$ siècle égyptien. Et, de fait, c'est à partir du règne de Méhémet Ali que la niqāba joua un rôle politique éminent, sous la houlette des cheikhs Bakrī, en devenant une institution étatique, reconnue officiellement par décret par le khédive 'Abbās Hilmī en $1895^{11}$. La niqāba fut étroitement liée à la dynastie égyptienne des descendants de Méhémet Ali, puis à la monarchie, et en général aux grandes familles qui constituaient les élites religieuses et sociales de la fin du XIX ${ }^{\mathrm{e}}$ siècle et de la première moitié du $\mathrm{xx}^{\mathrm{e}}$ siècle. Nombre des représentants des élites, dont le roi Farouk lui-même,

10 Winter, "The Ashrāf and Niqābat al-Ashrāf"; Winter, "The Ashrāf and the Naqüb al-Ashräf in Ottoman Egypt and Syria". Le second article n'ajoute rien au premier quant à l'Égypte, mais étend la description à la Syrie (notamment avec les cas d'Alep et de Jérusalem), d'après les archives ottomanes.

11 D'après l'article bien informé, daté de 2010 et fruit d'une enquête de terrain à la niqāba, dû à Charbel, "Egypt's Oldest Surviving Syndicate". 
appartenaient à la liste des membres de la niqāba au moment de la révolution de $1952^{12}$. Belle époque : le docteur Nabill, l'un des membres du Comité, est professeur d'histoire à l'université de Kafr al-Shaykh. Spécialiste de l'Égypte de l'entre-deux-guerres, il décrit avec regret cette période comme un âge d'or, pour l'Égypte comme pour la niqāba.

Si les ashrāfégyptiens appartenaient à des classes sociales variées, ce sont les cheikhs azhariens d'envergure et les grands cheikhs soufis qui tinrent le haut du pavé à la niqāba au XIX ${ }^{\mathrm{e}}$ et au début du XX $\mathrm{X}^{\mathrm{e}}$ siècle. Au premier rang, les cheikhs al-Sādāt et les cheikhs Bakrīin ${ }^{13}$. Les cheikhs soufis à la tête des grandes familles d'ashrāf et descendants de saints devinrent de grands propriétaires terriens lorsque, au milieu du XIX ${ }^{\mathrm{e}}$ siècle, se constituèrent dans l'entourage du khédive de grandes propriétés ; mais la fortune comme la notoriété de ces familles d'ashrāf avaient précédé les réformes égyptiennes du XIX ${ }^{\mathrm{e}}$ siècle, et dataient à tout le moins du XVIII ${ }^{\mathrm{e}}$ siècle, grâce à l'iltizām, voire remontaient jusqu'à l'époque mamelouke : c'est le cas par exemple des familles al-Qașabī et al-Ṣāwī, toutes deux affiliées à la Khalwatiyya, et de la famille Sharnūbī, branche de la Burhamiyya ${ }^{14}$. Dans ces « confréries héréditaires » (țuruq wirāthiyya), se jouent de fortes continuités, caractéristiques des élites religieuses égyptiennes : on est frappé de voir certains de ces noms toujours présents aujourd'hui à al-Azhar, au Haut Conseil des confréries soufies et dans les milieux proches du pouvoir à l'époque du président Moubarak. Jacques Berque, repris par Michael Winter, signalait à propos de Sirs al-Layyān, dans le Delta, que la prolifération numérique du nombre d'ashrāf au $\mathrm{xx}^{\mathrm{e}}$ siècle avait contribué au déclin de leur poids social, tandis que $\mathrm{H}$. 'Ammar signale à la même époque, dans son village de Haute-Égypte, qu'ils avaient réussi à maintenir, notamment en tant que maires de village ('umda), des positions stratégiques de pouvoir ${ }^{15}$.

12 Charbel, "Egypt's Oldest Surviving Syndicate".

13 Dans son livre de référence, Fred De Jong a rendu compte, d'après les archives des cheikhs Bakrī, du milieu confrérique qui gravitait autour de l'État égyptien. À partir d'al-Jabartī et de 'Alī Pacha Mubārak, et de sa très bonne connaissance d'al-Azhar, Gilbert Delanoue dresse un tableau convergent dans Moralistes et politiques musulmans.

14 Nous citons ici des exemples que nous avons pu rencontrer dans nos recherches sur le Delta, mais ils sont également très nombreux en Haute-Égypte. Sur la famille et confrérie Qașabiyya, qui mériterait une étude, cf. Mayeur-Jaouen, Histoire d'un pèlerinage légendaire en islam, 228-29, 235; sur Aḥmad al-Ṣāwī, cf. Mayeur-Jaouen, "The Small World of Aḥmad al-Ṣāwī (1761-1825)"; enfin, sur les continuités de la famille-confrérie Sharnūbī, Mayeur-Jaouen, "Nasab, Baraka and Land". Sur ces continuités, voir aussi Chih, Sufism in Ottoman Egypt.

15 Berque, Histoire sociale d'un village égyptien, 62; Ammar, Growing Up in an Egyptian Village, 47. Cités par Winter, "The Ashräf and Niqäbat al-Ashraf", 28. 
Il y eut pourtant rupture lorsque, un an après le coup d'État des Officiers libres de 1952, la niqāba fut dissoute en 1953 par le Conseil révolutionnaire, au motif qu'il ne s'agissait pas d'un syndicat professionnel, et qu'il fonctionnait par définition sur une base héréditaire contraire aux principes constitutionnels. La République, proclamée en 1953, avait aboli les titres de noblesse comme pacha ou bey: comment n'eût-elle pas aboli une organisation qui distinguait les ashrāf pour en faire une élite? La révolution ne pouvait les laisser subsister de façon organisée et institutionnelle. La volonté de rupture avec une tradition perçue comme passéiste allait de pair avec la modernité de l'Égypte nassérienne.

Cette histoire faite de grands noms, de hiérarchie et rythmée par l'État égyptien, unie autour des figures des naqībs, n'est pas seulement celle qu'ont reconstituée les historiens qui s'y sont intéressés : c'est aussi l'histoire que la niqāba donne à voir d'elle-même. Dans l'un des salons d'apparat qui jouxtent le bureau du naqīb, est affichée dans un cadre la liste bellement calligraphiée des douze noms de naqībs depuis les années 18oo jusqu'à aujourd'hui, avec les dates de leur office à la tête de la niqāba. Voici cette liste telle qu'elle est affichée ${ }^{16}$ : 'Umar Makram Ḥusayn al-Asyūṭī (de 1208/1792 à 1224/18o9); Muhammad Wafā 'Abd al-Ḥamīd al-Sādāt (de 1224/18og à 1228/1813); Muḥammad Aḥmad Muḥammad al-Dawākhilī (de 1228/1813 à 1231/1816); Muḥammad Muḥammad Abū l-Sưūd al-Bakrī (de 1231/1816 à 1271/1854); 'Alī Muḥammad Muhammad al-Bakrī (de 1271/1854 à 1297/1879); 'Abd al-Bāqī 'Alī Muhammad al-Bakrī (de 1297/1879 à 1309/1891); Muhammad Tawfīq 'Alī Muhammad al-Bakrī (de 1309/1891 à 1312/1895); 'Alī Muḥammad Aḥmad al-Biblāwī (de 1312/1895 à 1323/1905) ; Muḥammad 'Alī Muḥammad al-Biblāwī (de 1323/1905 à 1373/1953); Maḥmūd Aḥmad Kāmil Yāsīn al-Rifāīi (de 1411/1991 à 1415/1994); Aḥmad Aḥmad Kāmil Yāsīn al-Rifā̄ì (de 1415/1994 à 1429/2008). Et enfin l'actuel naqūb, Maḥmūd al-Sharīf, depuis 2008.

16 De Jong propose, quant à lui, une liste des naqüb al-ashrāfégyptiens jusqu'à 1911, qui repose à la fois sur des documents d'archives de la famille Bakrī et sur les histoires familiales rédigées par le naqīb Muhammad Tawfīq al-Bakrī (1870-1932), Bayt al-sādāt al-wafā̉ìya, et Bakrī, Bayt al-Siddīq. La liste commence au milieu du XVIII ${ }^{\mathrm{e}}$ siècle avec Muḥammad Abū Hādī al-Sādāt, naqīb jusqu'à 1168/1754-55, réputé par al-Jabartī le premier Égyptien à avoir tenu l'office de naqüb al-ashrāf avant de devenir cheikh de la Wafāiiyya en 1171/1758. Lui succède comme naqüb al-ashrāf Aḥmad b. Ismācīl al-Sādāt (de 1168/1754-55 à 1176/176263), devenu à son tour cheikh de la Wafāiiyya en 1762-63. À la famille des al-Sadat succède celle des al-Bakrī avec Muḥammad b. 'Abd al-Mun'im al-Bakrī (de 1176/1762-63 à ?), puis Aḥmad b. Muḥammad al-Bakrī ( ?-1195/1781), suivi de Muḥammad al-Bakrī al-Kabīr (de 1195/1781 à 1196/1782), puis de Muḥammad al-Bakrī al-Ṣaghīr (de 1196/1782 à 1208/1793) auquel succéda enfin 'Umar Makram, nommé naqīb par Méhémet Ali. Cf. De Jong, Țuruq and Turuq-Linked Institutions, 220-21. 
Il y aurait long à dire sur les silences d'une telle liste qui reprend une histoire étatique où tout commence avec Méhémet Ali. La formule est toujours identique, comme dans une chronique : « [Un Tel] a dirigé le Syndicat des descendants du Prophète de telle année à telle année » (tawallā niqābat al-ashrāf min 'ām ... hattā 'àm ...). Seule variante, la liste introduit pour les trois derniers naqïbs, à partir de la refondation de 1991, la mention : «par exécution du décret de la République égyptienne, numéro 54 de l'année 1991 » (bi-mūjib al-qarār al-jumhürī ...). Les ruptures politiques, l'Expédition d'Égypte (1798-18o1) comme la révolution nassérienne (1952), disparaissent presque, ellipses au profit d'une continuité manifestée par la calligraphie et les formulations identiques, d'un naqīb à l'autre, même si les années sont données - pour tous - à la fois en calendrier hégirien et en calendrier de l'ère chrétienne (mīlādì). La liste s'applique aussi à écarter les comparses et lâpre rivalité entre les Bakrī et les Wafā. Dans cette liste, ni sujétion ottomane, ni collaboration avec les Français : comme tout commence avec le célèbre 'Umar Makram, héros de la résistance aux Français et indiqué comme le naqüb en fonction de 1792 à 18og, on tait le nom de Khalīl al-Bakrī (m. 1223/18o9), pourtant nommé naqīb al-ashrāf par les Français en 1798 à la place de 'Umar Makram, enfui en Syrie avec Ibrāhīm Bey : Khalīl al-Bakrī fut destitué en 1801 par le pacha turc, et la charge de naqīb rendue à 'Umar Makram. La liste tait également le nom de Muhammad Abū l-Sưưd al-Bakrī (m. 1227/1812), cousin du précédent, nommé naqīb en 1801 par le gouverneur ottoman ${ }^{17}$. Quant à Muḥammad Wafā 'Abd al-Ḥamīd al-Sādāt ${ }^{18}$ (de 1809 à 1813) qui profita de la disgrâce de 'Umar Makram pour devenir naqīb, la liste en fait un simple successeur : «l'ordre des choses » remplace les luttes féroces pour le pouvoir.

Et lorsque s'affirme le retour de la maison al-Bakrī à la tête de la niqāba, rien ne transparaît de l'affirmation du pouvoir autonome de Méhémet Ali contre la Porte, qui se jouait alors: si Muhammad Muhammad Abū l-Su'ūd

17 Sur tout ceci Delanoue, Moralistes et politiques musulmans, $1: 253-54 \mathrm{ng1}$.

18 Il est connu par les historiens, à commencer par son contemporain al-Jabartī, comme Muhammad Abū l-Anwār al-Sādāt (m. 1813). Al-Jabartī le dépeint "sous les traits d'un homme de religion qui sait admirablement utiliser les avantages de sa position pour acquérir influence, pouvoir et richesse, tout en gardant les dehors respectables qui conviennent aux membres de la classe des 'ulamâ' et aux sayyid", Delanoue, Moralistes et politiques musulmans, $1: 255$. La famille Wafā est aussi une confrérie, la Wafāìya, étudiée par McGregor pour l'époque médiévale dans Sanctity and Mysticism in Medieval Egypt. S'éteignant, la famille Wafã fut remplacée par la famille des cheikhs Bakrī, étudiée par Adam Sabra dans un livre en préparation, Aristocracy and Empire : A Family History of Ottoman Egypt (1517-180o). Voir Sabra, "Household Sufism in Sixteenth-Century Egypt". 
al-Bakrī fut nommé naqüb al-ashrāf par celui-ci en 1816, ce fut sans doute pour prévenir la venue d'un naqīb envoyé par Istanbul, ou les intrigues d'Aḥmad al-Sadāt pour obtenir un firman d'investiture de la Sublime Porte ${ }^{19}$. Les puissants cheikhs al-Bakrī cumulaient la direction de leur propre et puissante famille, la mashyakha des confréries soufies et le syndicat des ashräf, ce qui leur permettait de contrôler les revenus des awqāf al-ashräf, et leur enregistrement dans le registre des ashrāf (daftar al-ashrāf $)^{20}$. Le cheikh al-Azhar, Ibrahīm al-Bayjūrī, reconnut en 1847 la suprématie du naqüb al-ashrāf sur les loges soufies $(z a w \bar{a} y \bar{a})$, les lecteurs de Coran et les mausolées de saints ${ }^{21}$. Bref, à partir des années 1850, les cheikhs Bakrī jouissaient d'un pouvoir considérable. Revenons à la liste : au début du $\mathrm{xx}^{\mathrm{e}}$ siècle, la liste passe sous silence le second mandat (1903-11) problématique de Muhammad Tawfīq 'Alī Muhammad al-Bakrī, interné au Liban pour maladie mentale, pour le remplacer par de fausses continuités. Enfin, au Xx ${ }^{\mathrm{e}}$ siècle, après la mention des cheikhs Biblāwī, derniers naqïbs de la monarchie, la liste saute de 1953 à 1991 pour parvenir sans transition à la refondation de l'ère Moubarak.

À côté de cette liste officielle, dont les silences et les choix sont si parlants, sont accrochés dans le salon d'apparat de la niqāba, six grands portraits de naqībs. D'abord trois naqībs du XIX' siècle: le portrait de 'Umar Makram, au centre, est encadré par les photographies retouchées de Muhammad al-Biblāwī et de Muhammad Tawfīq al-Bakrī. On a donc retenu, de tous les cheikhs Bakrī, le dernier, Muḥammad Tawfĩq 'Alī Muḥammad al-Bakrī (naqüb de 1891 à 1895), peut-être parce qu'il incarnait les espoirs du réformisme musulman appliqué au soufisme. Quant à Muhammad al-Biblāwī, le dernier naqüb de la monarchie égyptienne, c'est peut-être la durée exceptionnellement longue de son mandat comme naqīb qui lui vaut cet honneur, ou le fait que les plus âgés des refondateurs de 1991 avaient encore pu le connaitre ${ }^{22}$. Là aussi, la volonté de continuité est manifeste.

Au-dessous figurent les photographies des trois naqïbs de la refondation: Muhạammad Kāmil Yāsīn, que l'on me présente comme «le cheikh de la totalité de la confrérie Rifāiiyya et le président du Conseil scientifique de la société

19 Sur lui, Delanoue, Moralistes et politiques musulmans, 254n191; Jabartī, 7 :343-44, 9 :16869 ; Mubārak, Khițaț, 3 :125 ; Bakrī, Bayt al-Ṣiddīq, 44-46.

$20 \quad$ Sur tout ceci, la référence reste De Jong, Țuruq and Ṭuruq-linked Institutions, 32-33. Désormais, consulter Mughazy et Sabra, The Merits of the Bakrī Lords. An Anthology.

21 De Jong, Țuruq and Țuruq-linked Institution, 33-34.

22 Renaud Soler me signale aimablement que Biblāwī (m. 1953) est l'auteur de livres sur l'hégire et sur l'inimitabilité du Coran, parus en 1927 dans un contexte d'affirmation d'un islam menacé par la modernité, Biblāwī, Tārīkh al-hijra wa-bad' al-islām; Biblāwī, al-Ta'rīf bi-l-nabìwa-l-qur'ān al-sharîf. 
Ciba Geigy » (shaykh 'umūm al-țariqqa al-Rifāiiyya wa-ra'̄̌s majlis shirkat Sigaygī $a l$-'ilmī $)^{23}$. À côté, la photographie de son frère Aḥmad Kāmil Yāsīn qui lui succéda à la fois à la niqāba et à la tête de la confrérie Rifāiiyya. La dernière photographie est enfin celle du naqīb actuel, al-Sayyid Maḥmūd al-Sharīf, en fonction depuis 2008, issu d'une grande famille d'Akhmim (gouvernorat de Sohag). Les photographies, comme la liste, attestent que la niqāba s'inscrit dans une construction historique et un récit institutionnel qui sont ceux de l'État égyptien moderne : tout commence avec Méhémet Ali - le fait du prince - et tout continue en 2008 avec le décret qui nomme le naqīb actuel - le fait du prince, toujours, même s'il sanctionne une cooptation et émane désormais de la République arabe d'Égypte. Comme la suppression de la niqāba en 1953 est passée sous silence, on en oublierait presque que tout finit avec Nasser.

Il existe un autre récit de l'histoire de la niqāba et de ses origines, celui que propose le naqīb en personne, où tout commence, non avec Méhémet Ali, ni même exactement avec le Prophète, mais avec les ahl al-bayt d'Égypte. À la mi-septembre 2017, al-Sayyid Maḥmūd al-Sharīf accepte aimablement de me recevoir malgré ses obligations (il est vice-président du Parlement) et me narre une histoire «intérieure » de la niqāba qui insiste moins sur les ruptures que sur les continuités, moins sur l'institution que sur le rôle religieux, moral et spirituel des ashräf, moins sur l'État égyptien que sur le lien des ashräf avec le Prophète, leurs qualités et la moralité particulière à laquelle les destine leur généalogie ${ }^{24}$. Le $n a s a b$, pose fermement le naqīb, est un héritage (wirātha). Son discours ouvre, en guise de préambule, sur l'unité nationale dont le ferment, y compris dans la bonne entente revendiquée avec les coptes, est profondément celui de l'islam des origines : au rebours du récit généalogique habituel en culture islamique (on prend un individu et on énumère, de fils en père, toute son ascendance : fils de, fils de, etc.), il ne s'agit pas de remonter jusqu'au Prophète, mais de partir de ses descendants immédiats. Dans son récit, le naqīb commence donc avec les Gens de la Maison (ahl al-bayt), rappelle Fāțima al-Zahrā et sa descendance (dhurriyya) via Ḥasan et Ḥusayn.

23 Il s'agissait apparemment de la compagnie pharmaceutique suisse Ciba-Geigy. Peut-être les réductions de médicaments et l'accès à des soins médicaux bon marché proposés par la niqāba à ses membres viennent-ils de cette origine.

24 Je transcris ici un entretien téléphonique avec le naqīb al-Sayyid Maḥmūd al-Sharīf, le 15 septembre 2017, qui a pris la forme d'une sorte de cours donné dans un arabe littéraire élégant. J'ai ensuite rencontré le naqīb deux jours plus tard pour un entretien plus informel, en dialecte égyptien. On trouve le même récit (les passages sur les coptes en moins) dans une vidéo de quatre minutes, où s'exprime le naqüb, mise en ligne le 4 juillet 2016 sur Miṣr al-'arabiyya. Notons que la vidéo, en trois ans, n'a recueilli que très peu de vues. 
Moment déterminant puisqu'un sharîf descend de l'un ou de l'autre, ce qui fait de lui un hasanide ou un husaynide. Fille de Fāțima, petite-fille du Prophète, sœur de Ḥasan et de Ḥusayn, Sayyida Zaynab vint en Égypte en 61/68o-81: à partir de là, dit le naqüb, les descendants du Prophète se multiplièrent en Égypte et c'est pour les regrouper que fut fondé, en 247/861-62 le Syndicat des ashräf (niqābat al-sādāt al-ashräf). Comme l'avait remarqué Louis Massignon à propos de la Cité des morts et du culte des ahl al-bayt, on n'a pas assez commenté ce rôle prédominant, exorbitant, que les femmes jouent dans l'histoire de l'islam égyptien, et qu'un tel récit pose d'emblée ${ }^{25}$.

Al-Sayyid Mahmmūd al-Sharīf poursuit ses explications : le premier naqīb fut le chef de la famille (kabir al-'ầila), choisi pour sa popularité auprès des ashräf comme auprès des Égyptiens en général, pour sa moralité et pour son instruction religieuse (tarbiya dìniyya). La niqāba qui était chargée de veiller sur les fondations pieuses des ashräf, avait surtout comme but essentiel de propager l'islam par la $d a^{c} w a$, un islam fondé sur la justice, le juste milieu et l'absence d'extrémisme (al-itidāl wa-l-wasațiyya wa-ghayr al-tațarruf). Comme le naqīb s'adresse à moi, une Européenne, et que de récents attentats dus à Daesh ont cruellement atteint les coptes égyptiens, il insiste à nouveau sur les bonnes relations qu'a entretenues la niqāba avec les coptes à l'époque médiévale. Mais il parle plutôt de «chrétiens » (masīhiyyìn) que de coptes (aqbāt $)$, de leur nécessaire entente réciproque, de leurs visites mutuelles à l'occasion des fêtes, et du rôle que devait, que doit toujours jouer, le naqīb dans cette bonne entente. Après l'évocation de l'époque médiévale, le naqīb ne dit rien de l'époque ottomane ni du XIX ${ }^{\mathrm{e}}$ siècle, devenu anecdotique alors qu'il jouait le premier rôle dans la liste affichée. Quant à la suppression officielle de la niqāba en 1953, elle s'apparente d'après le naqüb davantage à une invisibilité qu'à une réelle disparition, et ne dura qu'une brève période (fatra) liée à la présidence de Nasser. À l'époque nassérienne, selon lui, on continuait à enregistrer les généalogies de certaines familles d'ashräf, dans le petit bureau d'une administration sous contrôle étatique (peut-être au ministère des Waqfs? ou au ministère de l'Intérieur?). Toujours selon le naqīb, la niqāba réapparut de façon officieuse sous Sadate, puis de façon officielle en 1991 sous Moubarak. Le siège en fut d'abord la maison même du naqīb refondateur, jusqu'à ce que la niqāba déménage en 2003 dans le bâtiment actuel, construit en 2002.

25 La venue de Sayyida Zaynab en Égypte semble légendaire, et l'on n'a pas de traces de vénération du sanctuaire avant le début de l'époque ottomane. Son tombeau existe également à Damas où il est devenu le centre important d'une piété chiite ravivée par la politique de l'Iran, désormais allié à la dynastie alaouite des Assad. 
Le récit du naqīb insiste résolument sur les continuités de la niqāba et de l'histoire des ashrāf: Méhémet Ali n'était qu'un jalon dans une histoire ininterrompue ; la révolution nassérienne était un épiphénomène; la refondation de 1991, un simple retour à la normale ; et la révolution de 2011 a passé, comme passe un vent mauvais. La niqāba est toujours là, insensible en apparence à l'écume des jours. Lorsque le naqīb me montre sur son téléphone portable sa photographie, prise quelques mois plus tôt, avec le président François Hollande venu en visite en Égypte, c'est pour l'anecdote francophile. Il tient surtout à redire la neutralité politique de la niqāba qui lui aura permis de franchir sans encombre les affres de la révolution et des années troublées qui suivirent, puisque la niqāba n'aura fermé que deux semaines au début des événements révolutionnaires. Le rôle du naqīb, rappelle-t-il, est de grouper tous les ashrāf, quelle que soit leur tendance politique, et de conseiller le président dans le sens de la sagesse et du bon sens. Il évoque notamment les conseils de modération qu'il avait donnés au président Frère musulman, Morsi (201213), en regrettant que celui-ci ne les ait pas suivis. Malgré les protestations de neutralité politique, pourtant, l'attachement au principe généalogique installe les ashräf dans un camp, celui de la tradition et de l'héritage, non de la révolution et de la rupture. Mais la tradition peut être révolution : c'est sans doute pourquoi certains membres du Comité protestent contre l'ordre social imposé par les nouveaux riches et le pouvoir de l'argent dans un monde néo-libéral. Ils parlent aussi, à mots couverts, contre la dictature (le directeur du Comité a même refusé de voter lors du référendum constitutionnel d'avril 2019, affirmant son affection pour le modèle libéral britannique). La « révolution des Gilets jaunes» en France a suscité de leur part beaucoup d'intérêt, voire de sympathie, tout en déplorant les excès qui, comme dans la révolution de 2011, ont terni le mouvement. Le plus jeune fonctionnaire du Comité, Aḥmad Yusrī, qui a participé à la révolution du 30 juin et à celle du 3 juillet (pour renverser le régime des Frères musulmans) est même militant du parti Hizb al-Miṣriyyīn al-Ahrār fondé par l'homme d'affaires copte Naguib Sawirès en 2011 contre les Frères musulmans, pour combattre la pensée terroriste, notamment sur le Net, et défendre la cause du dialogue des civilisations (ḥiwār al-hadāarāt). Pour Ahmad Yusrī, la niqāba est toutefois pleinement autonome : elle marche avec l'État, mais hors de la politique; elle soutient l'État (dāina li-l-dawla), joue un rôle national (lahā dōr wațan̄i) mais ce n'est pas un parti.

Le naqīb ne s'aventure pas dans de tels débats : pour lui, l'éthique des ashrā $f$ compte davantage que leur histoire événementielle. À son instigation, l'engagement religieux et moral auquel souscrivent les ashräf lorsqu'ils reçoivent leur «carte» figure dans un petit livret (sorte de carnet de famille). Le feuillet d'une page insiste sur les qualités morales que se doit d'observer un descendant 
du Prophète. Loin de s'enorgueillir d'une quelconque supériorité sur autrui, le sharîf doit - en imitant le Prophète - se rendre digne de sa noble ascendance.

\subsection{Au nom de Dieu le Clément le Miséricordieux}

Frère Sharīf, [sache] que ton intisāb aux Gens de la Maison ne t'accorde aucun privilège par rapport aux autres gens, mais qu'il est un honneur qu'orne la piété en Dieu Très Haut, qui a dit : « En vérité, le plus en honneur d'entre vous auprès de Dieu est le plus pieux » (Q $49: 13)$.

À toi de prendre exemple sur notre seigneur l'Envoyé de Dieu (la prière et le salut de Dieu soient sur lui). Repens-toi auprès de Dieu chaque jour, car lui (la prière et le salut de Dieu soient sur lui) se repentait cent fois par jour, et priait Dieu en secret et publiquement. Et sache que [recevoir] l'aumône (șadaqa) n'est pas permis à l'Envoyé de Dieu (la prière et le salut de Dieu soient sur lui), ni aux Gens de sa Maison. À toi d'obéir et d'abonder en prières et œuvres surérogatoires (nawāfil) et en travail ('amal) dans la vie, car l'islam est religion (dīn) et [action dans l']ici-bas $($ dunya $\bar{a}$.

Conforme-toi à la bonne nature [du Prophète], car le plus proche de l'Envoyé de Dieu - la prière et le salut de Dieu soient sur lui - est le meilleur en vertus $(a k h l a \bar{q})$. À toi de veiller au lien de famille (șilat al-arhạm) et à la prière, tandis que les gens dorment.

Sache que ton honneur à porter ce nasab t'oblige à être un exemple (qudwa) pour autrui, en obéissance et en bonne tenue (istiqāma) jusqu'à ce que tu obtiennes le mérite et la position qu'a annoncés l'Envoyé de Dieu (la prière et le salut de Dieu soient sur lui) d'après la version d'Ibn 'Abbās (que Dieu ait pitié d'eux deux) : « Le Prophète a dit: 'Chaque cause (sabab) et chaque généalogie (nasab) s'interrompront au Jour de la Résurrection, sauf ma cause et ma généalogie' (Ṭabarānī, repris par Haythamī (sic) dans Majma 'al-rawāid wa-rijälihi) ». Ces deux récits, l'un institutionnel et politique, l'autre religieux aux accents moralisateurs et finalement eschatologiques, sont construits en miroir, jusqu'à un certain point: à l'importance du territoire égyptien à l'époque médiévale (discours du naqīb) répond l'affirmation de l'État égyptien au XIX ${ }^{\mathrm{e}}$ siècle (discours de la niqāba), aux ahl al-bayt émigrés et vénérés en Égypte, comme Sayyida Zaynab (discours du naqīb), répond l'importance des confréries soufies (discours de la niqāba), à la famille d'origine, celle du Prophète (le naqīb), répondent les grandes familles de ses descendants, à l'époque ottomane et khédiviale (la niqāba). Mais qu'ils mettent l'accent sur l'institution ou sur le rôle religieux, quel que soit le choix qu'ils font de la périodisation, les deux récits comprennent chacun des accélérations et des omissions, dans le but commun 
d'insister sur la continuité de la niqāba et des ashrāf. Les deux récits omettent finalement de dire pourquoi et comment la niqāba a été refondée en 1991.

\subsubsection{1 : la refondation de la niqāba égyptienne, un acte politique à l'époque de la guerre du Golfe}

Il faut sans doute comprendre la refondation de la niqāba en 1991 comme un aspect de la réhabilitation de la période monarchique entreprise sous Moubarak, au même titre que les dédommagements octroyés aux propriétaires spoliés par les nationalisations de l'époque nassérienne, et que la reconstitution de grandes fortunes foncières, défaisant les lois de réforme agraire.

Indépendamment de ce contexte général, pourquoi refonder la niqābat al-ashrāf en 1991? Le dr. Sulaymān, directeur du Comité de vérification des $a n s a \bar{b}$, a son hypothèse : c'est la rivalité avec l'Irak qui explique cette refondation. Lors de la guerre du Golfe, au tout début de 1991, Saddam Hussein avait créé une niqāba irakienne pour attester son propre nasab de descendant du Prophète ${ }^{26}$ : l'orgueil égyptien fut piqué au vif, et, toujours d'après le docteur Sulaymān, un entourage de conseillers (mustashārūn) qui réclamait depuis longtemps au président Moubarak la refondation officielle de la niqābat al-ashräf obtint gain de cause. Rappelons que l'Égypte participait alors à la guerre menée par les alliés sous l'égide de l'ONU, contre l'Irak envahisseur du Koweït : la niqāba égyptienne, à peine refondée, se posait donc en rivale de la niqāba irakienne, et l'islam égyptien se prévalait du même coup d'une supériorité intrinsèque.

Peut-être cette compétition en matière de légitimité islamique et de leadership sunnite est-elle liée à une rivalité plus complexe encore : le nouveau naqīb égyptien, riche homme d'affaires lié au régime Moubarak, était aussi le cheikh de la confrérie Rifāiiyya en Égypte, soit une confrérie d'origine irakienne, dont le fondateur éponyme, Aḥmad al-Rifā̄ì (m. 578/1182) est précisément enterré en Irak. L'un de ses descendants, 'Alī al-Rifāī dit Abū l-Shibbāk, est enterré et vénéré au Caire près de la Citadelle, dans un vaste mausolée construit entre 1869 et 1912, en face de la mosquée du sultan Ḥasan. De façon significative, la construction du mausolée était commanditée par la mère du khédive Ismaïl, Khoshyar Hānem, et le mausolée devint effectivement celui de plusieurs membres de la famille royale, dont le roi Farouk. Mais c'est en l'honneur du saint Rifāīi qui y est enterré qu'est célébrée chaque année une fête, le mouled d'al-Rifāìi. Face à Saddam Hussein qui revendiquait désormais

26 Sur la légitimation islamique de l'Irak de Saddam Hussein, et le lien inattendu entre Rifāiciyya et Baas, voir la thèse toute récente de Jordan, "The Rifāicyya in 2oth-Century Iraq". 
son identité de sharîf et ses liens avec la Rifāiiyya, l'affirmation égyptienne permettait de rappeler la primauté et la centralité de la niqābat al-ashrāf en Égypte, en même temps que la force de la Rifāiiyya égyptienne. À ce début des années 199o, la Rifāiiyya égyptienne vivait une période faste de son histoire, et le mouled d'al-Rifāc̄i était à son pinacle, avec de grandes processions, des foules de participants, des tentes de pèlerins, des costumes et des bannières toutes neuves ${ }^{27}$. Un livre de photographies de mouleds, publié en 1999, atteste de cette particulière splendeur des mouleds Rifāī des années 1990: on y voit le naqüb al-ashrāf, enturbanné et drapé de noir, comme il sied à un cheikh rifāàì, chevaucher lors de la procession vespérale, à la tête d'une foule considérable ${ }^{28}$. Bref, les cheikhs Aḥmad Kāmil et Muhammad Kāmil, naqüb-s refondateurs, ne dissociaient guère niqāba et tarīqa.

$\mathrm{Au}$ moment de la refondation, un Conseil supérieur de la niqāba (ou Conseil supérieur des ashrāf, al-majlis al-alā li-l-ashrāf) fut constitué, dont les membres étaient - et sont toujours - de riches hommes d'affaires. Quant aux participants à la réunion de refondation, il s'agissait, me dit-on, des « chefs de familles des ashräf» (kibār 'äilät al-ashrāf). Ce dernier terme revient souvent, à propos de l'établissement des généalogies : sans correspondre à un statut précis, il renvoie à une réalité prégnante de la société égyptienne. Les « élections » de 1991 - intikhābāt, c'est le terme employé par mon interlocuteur - furent en fait une cooptation au sein des grandes familles d'ashräf, et c'est ainsi que fut choisi comme naqūb Aḥmad Kāmil Yāsīn, cheikh de la confrérie Rifāiiyya en Égypte. La réalité comme les activités de la niqāba furent d'abord modestes, avant l'installation dans le nouveau bâtiment en 2003: le Comité alors dirigé par Aḥmad Yahyyā ne comptait que trois membres, contre neuf aujourd'hui, et il se tenait dans les bureaux mêmes de la société pharmaceutique dirigée par le $n a q i \bar{b}$.

Le soutien de l'État et son autorisation étaient indispensables à cette refondation, et plusieurs membres influents de la niqāba étaient liés au Parti national démocratique alors au pouvoir (le PND), sur un modèle similaire à celui qui liait les cheikhs al-Tayyib de Gourna et le PND sous le régime Moubarak ${ }^{29}$. Depuis 1991, la niqāba est donc une institution paraétatique, liée aux milieux de pouvoir et aux milieux d'affaires de l'Égypte de Moubarak. Né vers 1955,

27 En témoignent deux livres : Biegman, Moulids, Saints, Sufis : Egypt, $3^{1}$ (photographie du mouled Rifāīi en 1988); et Mayeur-Jaouen, Pèlerinages d'Égypte.

28 Mulid! Carnivals of Faith, photographies de Sherif Sonbol, textes de Tarek Attia, The American University in Cairo Press, 1999 (les pages et les photographies du livre ne sont pas numérotées). Les auteurs du livre n'ont pas identifié le cheikh des confréries rifā̄ī comme le naqīb.

29 Chih, Le soufisme au quotidien. 
l'actuel naqīb lui-même, issu d'une grande et riche famille d'ashrā $f$ de la région d'Akhmim, est député au Parlement égyptien depuis 199o, soit avant même la refondation officielle de la niqāba. Devenu naqūb, traversant sans dommage les aléas de la révolution de 2011 (grâce à sa neutralité, souligne-t-il lui-même), il est depuis peu vice-président du Parlement (wakīl awwal li-l-barlamān al-mișrî̀). Sans être élu, il figure sur la liste de noms (qä̉ima) imposée par le gouvernement. C'est dire si son influence comme naqīb, si discrète soit-elle, s'accompagne d'un poids réel dans la nomenklatura égyptienne. Le naqīb y insiste: le rôle politique qu'il dit jouer « comme un citoyen au service de la nation » (ka-muwāțin fi khidmat al-wațan) doit être dissocié de son rôle comme naqüb, qu'il assimile plutôt à un rôle représentatif et diplomatique. Il représente les ashräf et entretient de bonnes relations avec les institutions religieuses de l'État ou liées à l'État, qu'il énumère ainsi: la mashyakhat al-Azhar, le dār al-iftä', le ministère des Waqfs et la mashyakha āmma du Haut Conseil des confréries soufies, enfin l'Église égyptienne dans toutes ses composantes (al-kanisa al-mișriyya fì jamì al-țawāìf). Nous retrouvons ici les institutions de l'islam d'État évoquées au début de cet article. La mention de l'Église égyptienne est sans doute moins attendue, mais occupe la place qui lui est assignée, éminemment cléricale et subalterne, auprès de l'islam égyptien institutionnalisé.

La niqābat al-ashrāf de 1991 prenait donc, près de quarante ans après sa suppression, une visibilité et un rôle nouveau dans l'islam d'État égyptien à l'époque Moubarak.

\subsubsection{Ashrāf et soufis}

Sa refondation s'accompagnait d'un soutien délibéré aux confréries soufies, ou à certaines d'entre elles plus exactement. C'est même lors d'une réunion au siège de la confrérie soufie Hāmidiyya Shādhiliyya ${ }^{30}$ qu'eut lieu le choix du nouveau naqīb. On l'a vu lors du récit de la première visite évoquée plus haut, plusieurs des fonctionnaires de la niqāba portent des bagues comme on le fait dans le milieu soufi, plus exactement un gros anneau d'argent serti d'une pierre semi-précieuse de couleur. Pourtant, tous les soufis ne sont pas ashräf, et inversement, tous les ashräfne sont pas nécessairement soufis. Certains sont même hostiles au soufisme, voire salafistes. Mais prévaut, dans les deux univers, la prédominance du lien généalogique (la șila, souvent invoquée à la niqāba), ce qui contribue à les rapprocher : un cheikh soufi est en général le fils d'un autre cheikh soufi (même si ce n'est pas obligatoire), tandis qu'un sharīf est, par définition, le fils d'un autre sharîf. 
D'autre part, les cheikhs soufis descendent généralement de saints musulmans - lignées héréditaires de la baraka, maintes fois décrites par des spécialistes $^{31}$ - tandis que les ashräf, même non soufis, descendent bien souvent, eux aussi, de saints musulmans. C'est la sainteté qui aura permis de « fixer » le sharaf. Le directeur du Comité de vérification des ansāb me rappelle que les quatre Pôles à l'origine même de la plupart des confréries soufies (du point de vue égyptien), soit Aḥmad al-Rifāīi, 'Abd al-Qādir al-Jīlānī, al-Sayyid al-Badawī, et Ibrāhīm al-Disūqī, étaient tous quatre ashrāf: il s'agit donc d'une relation naturelle, selon lui, qui va de soi.

$\mathrm{Au} \mathrm{XIX}^{\mathrm{e}}$ siècle et dans la première moitié du $\mathrm{XX}^{\mathrm{e}}$ siècle, comme lors de sa refondation, la niqāba était liée aux confréries soufies, on l'a vu, d'un lien constitutif et ancien. Dès l'époque mamelouke, les cheikhs soufis comptaient parmi les notables ruraux, ceux qui allaient précisément s'attacher à un nasab et en préserver à la fois le souvenir et la trace matérielle. Au XIX ${ }^{\mathrm{e}}$ siècle, les cheikhs Bakrī présidèrent à la constitution du Haut Conseil des confréries soufies, en même temps qu'ils faisaient office de $n a q \bar{\imath} b$-s de l'Égypte monarchique, et l'on sait le rôle que le cheikh Tawfìq al-Bakrī, qui fut naqīb, joua dans la réforme du soufisme égyptien des années $1900^{32}$. Les ashräf de l'entourage de Moubarak, qui militèrent pour la refondation de la niqāba en 1991, étaient bien les héritiers de familles illustres dans le monde du soufisme égyptien, et non des homines novi: ils surent pourtant se concilier le soutien d'hommes d'affaires qui ne descendaient en rien de ces notables d'antan.

En 1991, non seulement le premier naqüb de la nouvelle niqāba était le cheikh de la confrérie Rifāiiyya pour toute l'Égypte, mais il veilla à nommer des Rifā̄īs aux postes-clés de la niqāba: Aḥmad Muhammad Khalīfa à la comptabilité et Aḥmad Yahya à la tête du Comité de vérification des généalogies, dont il fut le premier directeur. Ce dernier, diplômé d'une faculté de commerce, travaillait alors en Arabie saoudite. Lorsque le naqūb le fit revenir en Égypte pour diriger le Comité, Aḥmad Yahyā, de son propre aveu, ignorait tout de la science de la généalogie, mais en devint rapidement, à en juger par son actuelle dextérité à manier les références, à repérer les erreurs de telle encyclopédie, et à lire les manuscrits, un excellent spécialiste. Quelles que soient sa vivacité intellectuelle et son énergie, toujours manifestes près de trente ans après sa nomination, c'est son rang élevé dans la hiérarchie de la Rifāiciyya qui le désignait

31 Parmi les meilleurs ouvrages sur un sujet bien connu, cf. Peskes, al-Aidarus und seine Erben; et Sedgwick, Saints and Sons.

32 Sur ce personnage, De Jong, Țuruq and Țuruq-Linked institutions; et Mestyan, "al-Bakrī, Muhammad Tawfïq". 
à l'attention d'Aḥmad Kāmil Husayn dont il était le bras droit à la confrérie comme à la niqāba.

À la niqāba, quelle que soit la prudence affichée en ces temps postrévolutionnaires où le Syndicat a traversé sans encombre le régime des Frères musulmans et la montée des salafistes, le lien privilégié entre monde des confréries soufies et niqāba est partout présent, partout visible. On voit affichée sur le palier du quatrième étage une grande photographie où le naqīb Sayyid Maḥmūd al-Sharīf pose aux côtés du cheikh 'Abd al-Hādī al-Qașabī, lui aussi député, cheikh du Haut Conseil des confréries soufies, lors du mouled d'al-Jazūlī en juillet $2011^{33}$. C'est bien un milieu de l'establishment soufi d'État qui a refondé la niqāba égyptienne, et qui continue à l'animer.

\subsection{Une administration hiérarchique liée à l'État, mais autonome}

Liée à l'État égyptien, la niqāba est pourtant une administration autonome, avec un budget propre, financé par les cotisations de ses adhérents et par les dons des membres les plus fortunés des milieux d'affaires liés aux ashräf. Elle ressemble à d'autres administrations égyptiennes : elle ferme le vendredi et le samedi, ouvre du dimanche au jeudi de $9 \mathrm{~h} 30$ à $15 \mathrm{~h} 30$ (avec un pic de fréquentation de $11 \mathrm{~h}$ à $13 \mathrm{~h}$ ), modifie ses horaires durant Ramadan. Elle recourt peu au numérique (en fait uniquement pour établir les cartes de membres du Syndicat), s'appuie essentiellement sur des documents manuscrits sur papier, et prône le souci des relations personnelles directes. On ne traite ni par téléphone, ni par quelque site dématérialisé: la quête du nasab est affaire de rencontre et de plaidoirie. Le demandeur de nasab (qui reste généralement debout) entre dans la salle du Comité pour plaider sa cause lui-même, présenter son dossier, donner des explications et négocier directement avec les membres du Comité (qui restent assis).

De nombreux indices permettent de deviner qu'il s'agit d'une administration autonome, qui rémunère ses propres employés sans le secours de l'État: le bâtiment est très propre, l'accueil soigné, et le travail réel, et même efficace. Ici, pas d'employés fictifs ou de plantons inemployés, pas de bureaux en désordre, de cafétéria improvisée ou de gravats dans un coin. Au quatrième étage, où siège le Comité de vérification des ansāb, dans le grand hall où canapés

33 Le cheikh Qașabī a joué un rôle politique durant la révolution et sous les Frères, ce que désapprouvent les membres du Comité : selon eux, c'était superficiel, alors que le naqīb, en restant au-dessus de la mêlée, s'est montré sage - conforme au modèle de ce que doit être un sharīf. 
et fauteuils confortables permettent de patienter, sont partout affichés des modèles du certificat-type (la fameuse shahädat nasab), pour que les demandeurs aient immédiatement sous les yeux l'objet de leurs désirs. Couloirs et bureaux donnent sur ce hall central, à l'ambiance paisible, où l'on entend souvent la récitation du Coran en fond sonore. Le mobilier est récent et fonctionnel, les fonctionnaires sont souvent en complet-veston et en cravate, parfois en blouson de cuir - cher aux fonctionnaires égyptiens - même si les plus jeunes portent jean et polo. L'un des membres du comité, nubien peut-être, porte galabeyya et turban blanc, comme en Haute-Égypte: la majorité des visiteurs en quête de nasab sont eux aussi originaires du sud de l'Égypte. Les employés de la niqāba comptent fort peu de femmes, et aucune au Comité de vérification des généalogies. Elles sont généralement voilées (mais pas systématiquement), comme il devenu normal depuis des décennies en Égypte dans un milieu musulman et essentiellement masculin. Enfin, si la plupart des employés sont des ashräf, ils ne le sont pas nécessairement: choisi pour ses compétences scientifiques par le naqīb, le docteur Sulaymān n'est pas sharīf lui-même, même s'il se trouve que sa femme est sharîfa.

Le bâtiment compte six étages. Au premier étage, se trouve la salle de prière où se rendent ponctuellement les fonctionnaires pour les prières de midi et de l'après-midi, celles qui coïncident avec les horaires de bureau. Au deuxième étage, se trouve la bibliothèque de la niqāba, bien classée: des rayonnages de bois clair, bien éclairés, tapissent les murs de la pièce au centre de laquelle se trouvent des tables couvertes de piles de livres et de dossiers. Les rayonnages portent des étiquettes, désignant les rubriques: al-ansāb, al-alām, al-fiqh, al-tafsìr, al-taräjim ... Chaque année, deux membres du Comité se rendent à la Foire du Livre du Caire pour acquérir de nouveaux ouvrages sur la science des généalogies, à moins qu'ils ne les photocopient. Au troisième étage travaillent cinq calligraphes qui établissent les certificats de nasab et la copie finale de la généalogie. Au cinquième étage, se trouvent des salons de réception, le bureau du naqīb et celui de sa secrétaire. Ce bureau d'apparat est meublé de meubles incrustés de nacre, décoré de calligraphies coraniques. S'y trouve la bibliothèque personnelle du naqīb, où figure par exemple, en trois volumes, Fatḥī 'Abd al-Qādir Sulțān al-Ḥusaynī, Mawsū'at ansāb Āl al-bayt al-nabawì al-'arabiyya li-tawthìq al-ansāb, et un livre de Șalāḥ al-Dīn al-Qūsī, Dìwān al-mufíq al-shafí. Sur son bureau, trône le porte-plume offert par le ministère saoudien du Commerce et de l'Industrie, branche de Médine. Au sixième et dernier étage enfin, à côté d'une grande salle de réunion, une terrasse domine la ville, ornée d'une petite coupole verte. On y jouit d'une vue imprenable sur Le Caire, la Cité des morts, la falaise désertique (et désormais fort peuplée) du Moqattam et le Jardin d'al-Azhar créé par la Fondation de 
l'Agha Khan, juste en face de la niqāba. Cette terrasse ne sert guère que pour des invitations officielles.

Redescendons donc au quatrième étage: là siège le Comité de vérification des généalogies, composé de neuf membres, qui se réunit au complet deux jours par semaine, mercredi et jeudi, jours d'affluence maximale. Ceux des membres qui exercent ailleurs un travail rémunéré ne viennent que ces deux jours-là, et sont payés par session, comme le docteur Nabīl et le docteur Sulaymān, directeur du Comité de vérification des généalogies. Les autres jours ouvrables (dimanche, lundi, mardi), ce sont les quelques fonctionnaires permanents - notamment Aḥmad Yahya - qui se contentent de recevoir les dossiers et d'initier ou poursuivre les recherches. Mais ce n'est que le mercredi et le jeudi, lorsque tous ses membres sont réunis, que le Comité peut statuer sur l'acceptation ou le rejet d'une demande de nasab. Attention : le paiement n'a lieu qu'après que les neuf membres du Comité de vérification des ansāb ont tous validé et authentifié le nasab. On y a insisté très souvent auprès de moi. Cette insistance même atteste a contrario que nombre de rumeurs ont couru dans le passé, selon lesquelles il suffirait de payer pour se voir octroyer un nasab de sharif ${ }^{34}$. D'après mon observation, la plupart des procédures visent justement à éviter toute tentation de corruption, notamment par la réunion de neuf membres dont chacun doit approuver l'authenticité du nasab.

Au même étage que le Comité de vérification des généalogies se trouvent justement les bureaux du service des finances. Un fonctionnaire soufi, diplômé d'une faculté de commerce, s'occupe des paiements des taxes (rusūm), du budget, fait payer les abonnements et les carnets, préparés et rangés par piles dans son bureau, qu'il distribue sous enveloppe aux impétrants tout heureux, en leur disant « Félicitations » (mabrūk). La somme à payer, sans être excessive, n'est pas négligeable. Les chiffres de 2017, devenus dérisoires avec le flottement de la livre à partir de novembre 2016, n'étaient d'abord pas ridicules : la première inscription au syndicat (ishtirāk) coûtait 200 livres pour payer les frais de dossier, puis le renouvellement de l'inscription était de 8 o livres par an. En outre, il fallait payer 40 livres pour obtenir le «carnet » $(k a r n \bar{e})$, sorte de livret de famille du sharïf. Le sharïf nouvellement munassab devait donc payer 240 livres pour la première année : ces sommes, sans être élevées, n'étaient alors pas négligeables, si l'on considère par exemple que le salaire moyen d'un petit fonctionnaire était de 1,20o livres par mois (chiffre de 2017), et que tout le monde ne gagnait même pas ce salaire de fonctionnaire. Dérisoire pour des gens riches, encore accessible à la petite classe moyenne, le certificat ne le serait pas pour

34 Larticle de Jano Charbel fait allusion à ces rumeurs, notamment à propos de Kadhafi : celui-ci qui cherchait par tous les moyens à se voir reconnu comme sharîf (un point confirmé par les collègues marocains) aurait payé pour obtenir le certificat. 
les plus pauvres, d'autant que chaque adhérent - la plupart des visiteurs de la niqāba sont des hommes - paie aussi pour son épouse et ses enfants. Un grand nombre des demandeurs arrivent donc au bureau du Comité avec six ou sept dossiers dans les bras : soit 1,440 ou 1,680 livres à payer par an en perspective (en 2017). En échange, la carte ne donne pas droit à grand-chose de tangible: des réductions dans un réseau de médecins et d'institutions médicales, une éventuelle assistance financière dans certaines régions (Qinā). Il m’arrive de croiser dans l'ascenseur des rares membres réduits à la pauvreté - des veuves avec enfants, notamment - qui viennent, de loin en loin, à la niqāba, leur carte de membre à la main, chercher un secours financier auprès de la direction des finances.

Lécrasante majorité des Égyptiens qui viennent faire établir leur nasab et leur carte ne cherchent pas un avantage qu'ils ne trouveront pas, mais semblent y chercher plutôt la fierté (nü'min al-tafakhkhur, me dit-on), le prestige, un sentiment d'appartenance. Pour ceux qui travaillent dans le monde azharien, et en général dans le milieu religieux, être munassab est un «plus » incontestable. Pour les mieux insérés et les plus fortunés, la niqāba est plutôt un club, comme le serait le Rotary: des habitués viennent saluer chaleureusement les membres du Comité, prennent des nouvelles, en donnent, boivent un thé, repartent pour vaquer à leurs affaires.

Les tarifs ne sont pas les mêmes pour les demandeurs étrangers, nombreux à venir pour faire établir un certificat de nasab. Dans leur cas, contrairement aux Égyptiens, on ne se contente pas de copies de l'arbre généalogique, ils doivent présenter un original, et venir en personne - pas moyen d'utiliser un substitut. Les tarifs les concernant sont modulés selon la richesse ou la pauvreté de leur pays. Un Somalien ne paiera pas la même somme qu'un Saoudien, par exemple. Évidemment, il y a des cas compliqués, comme cet Allemand d'origine somalienne que je croise à la niqāba: quelle somme doit-il payer? Dans le cas des Jordaniens, d'après un témoignage recueilli à Amman auprès d'une famille venue demander une shahādat nasab à la niqāba égyptienne, il en coûte environ 400 dinars jordaniens (soit plus de 5 oo euros, chiffre de 2018) pour faire établir un certificat, même lorsque l'on dispose déjà d'un arbre généalogique attesté.

\subsection{Au cœur de la niqāba $:$ la vérification des ansāb}

Entrons donc dans le cœur de la niqāba, le Comité de vérification des ansāb. Il se tient dans une vaste pièce, bien éclairée par des néons, où des bureaux arrangés en fer à cheval encadrent la porte d'entrée. Jusqu'à neuf fonctionnaires s'y tiennent: ce sont les membres du fameux Comité, avec parfois quelques 
assistants qui vont et viennent, et Ḥasan, le sympathique planton chargé d'approvisionner en boissons les fonctionnaires, éventuellement les visiteurs (thé, café, infusion d'anis: yansūn). C'est une administration hiérarchique, mais dont la hiérarchie est duelle, puisque le comité a depuis 2008 deux directeurs qui siègent côte à côte. Le « directeur administratif » du Comité, Ahmad Yahyā, qui est fonctionnaire de la niqāba depuis la refondation, partage la direction avec le « directeur scientifique », le docteur Sulaymān, dont l'autorité n'est pas discutée : en cas de litige, c'est lui qui décide. Bien qu'il ne soit pas sharîf lui-même (ou peut-être à cause de cette neutralité même), le docteur Sulaymān, professeur à l'université de Kafr al-Shaykh, a été nommé en 2008 par l'actuel naqīb pour sa compétence scientifique sur les ansāb et les ashräfà l'époque ottomane.

Sur les différents bureaux, s'empilent de façon ordonnée de grands dossiers de couleur verte intitulés : Demande d'établissement et de révision de la généalogie (Ṭalab ithbāt wa-murāja'at nasab). Le Comité traite une cinquantaine de dossiers par semaine, en moyenne, moins pendant Ramadan, davantage pendant le mouled d'al-Husayn (pèlerinage au mausolée sis juste à côté d'al-Azhar) où affluent au Caire les ashrā $f$ de Haute-Égypte qui en profitent pour régler leurs affaires. De nombreux dossiers restent à l'étude, pendant des mois, parfois pendant des années. C'est à travers ces dossiers individuels et nominatifs qu'est traitée la délicate question de savoir si le demandeur est ou non un sharïf. On y recueille tous les documents nécessaires à l'authentification du nasab: par exemple les certificats de naissance des membres de la famille, des certificats de mariage, la copie d'un ancien arbre généalogique, la photocopie d'une page de livre imprimé où l'on retrouve mentionné tel ancêtre ou telle branche de la famille, enfin des photographies d'identité nécessaires pour établir la carte d'adhésion personnelle et nominative à la niqāba. Certains dossiers sont fort volumineux, et la photocopieuse et l'agrafeuse marchent bon train pour aider à remplir le dossier.

Pour devenir munassab - quelqu'un dont le nasab est établi comme sharîfil faut produire un arbre généalogique (shajarat al-cāila ou shajarat al-ansāb). «C'est la base », me dit-on (al-asās shajarat al-ansāb). Idéalement, le demandeur produit devant le Comité l'original, la fameuse rolla qu'évoquent plusieurs de mes interlocuteurs, faisant le signe significatif de dérouler un rouleau pour montrer la matérialité de l'archive. À titre d'exemple, Aḥmad Yahyā me montre, mis à l'abri dans des sacs en plastique, un rouleau de parchemin (d'époque ottomane?), rongé par les insectes. Doit-on, à chaque naissance, sortir le précieux document de sa réserve au risque de l'abîmer, et apporter à la niqāba cette preuve pour faire de l'enfant un munassab ? Le procédé est délicat, dangereux peut-être pour le précieux document. La famille détentrice de l'arbre, 
d'ailleurs, y consentira-t-elle? Eh bien, me dit-on, il suffit de photographier, grâce à un téléphone portable, le précieux arbre généalogique, puis de joindre le certificat de naissance (shahādat wiläda) où apparaît celui des parents qui est d'ascendance chérifienne, et de fournir les preuves de sa connexion avec l'arbre en question.

Que l'on procure l'original lui-même ou qu'on le produise sous forme photographiée ou photocopiée, où trouver cet arbre généalogique initial, qui est toujours - d'après mes constatations - une copie ottomane ou une copie datée du XIX ${ }^{\mathrm{e}}$ siècle d'un original plus ancien? On doit la chercher chez le chef de famille (kabir al-āàila), m'explique-t-on, soit le plus âgé, soit le plus expérimenté, soit celui qui a à la fois de la disponibilité et de l'influence, sans doute aussi aisance financière, voire richesse.

À ces considérations s'ajoute la taille de la famille qui peut grouper des milliers de personnes, hommes, femmes et enfants, lorsque la famille est liée à une confrérie soufie héréditaire. C'est le cas des Sharnūbī sur lesquels j'avais enquêté en 2010-13: dans cette importante famille, l'arbre généalogique initial - enjeu de pouvoir - était détenu dans une branche en particulier, mais un autre membre de la famille, lui-même cheikh soufi d'une autre branche, avait constitué un arbre plus restreint, où figuraient les femmes et les mariages, et l'avait numérisé sur son ordinateur. Et un troisième chef de famille Sharnubī, issu d'une autre branche encore, homme de pouvoir lié au PND, faisait le lien entre ces preuves dispersées et la niqāba: «c'est lui qui distribue les cartes», m'avait-on dit alors, au sens propre comme au sens figurée ${ }^{35}$.

La niqāba est en effet une institution centralisée dans un pays bureaucratique, pourtant ramifiée avec des relais locaux (par ville) dans les différents gouvernorats. Au XIX ${ }^{\mathrm{e}}$ siècle, 'Alī Pacha Mubārak raconte comment chaque district ou ville avait son wakülal-ashräf: la généalogie pourtant ne pouvait être prouvée qu'en écrivant au naqīb en personne, assisté de shāwissh, et en demandant une enquête dans les archives des fondations pieuses, et dans celles des gratifications octroyées aux ashrāf ${ }^{36}$. Aujourd'hui, dans la salle du comité, des classeurs étiquetés par gouvernorat contiennent les listes des instances locales, particulièrement actives en Haute-Égypte, surtout dans la région de Qinā, où le sharaf fait écho à des affiliations tribales. Parfois, le Comité entre en relation avec ces instances locales pour obtenir des renseignements sur les familles d'ashräf. Mais c'est au Caire qu'il faut monter pour obtenir la décision administrative finale sur le sharaf. Ainsi s'organisent des allées et venues avec la Haute-Égypte : un haut fonctionnaire du ministère de l'enseignement à

35 Mayeur-Jaouen, "Nasab, Baraka and Land".

36 Mubārak, Khițaț, 3 :134. Passage résumé par Winter, "The Ashrāf and Niqābatal-Ashrāf", 19. 
Assiout passe visiter le Comité, en ami, car il fait fréquemment la navette entre les deux villes. Il a d'ailleurs deux épouses (ce qui est rare en Égypte), l'une à Assiout, l'autre au Caire. Comme je l'interroge sur ce qui est le plus important, le sharaf ou la tribu, il élude : le sharaf donne un cadre général ...

On commence donc par l'arbre généalogique et par la différenciation, entre hasanī et ḥusaynī. Ensuite, m'explique Aḥmad Yahyaā, à partir du «nom de famille» ou assimilé, il faut établir la postérité de cette famille (táqīb al-dhurriyya). Pour ne pas se perdre, il faut ensuite repérer le 'amūd al-nasab, littéralement le «pilier du nasab », son pivot - c'est-à-dire l'ancêtre ou la figure célèbre dont le sharaf est indiscutable. Le terme est important : j'entends souvent, lors des discussions, Aḥmad Yahyā interroger le sous-fifre qui présente le dossier d'un demandeur: «Mais quel est le 'amūd al-nasab? » Il ne restera plus - mais ça peut être très compliqué - qu'à prouver comment le demandeur se rattache lui-même à ce pivot.

Autre point délicat: les arbres généalogiques arabes s'en tiennent en principe à la loi patrilinéaire et patriarcale, et ne font figurer ni les femmes ni les filles. Un nasab chérifien, pourtant, finit toujours par remonter, par définition, à une femme au moins, Fāṭima al-Zahrā', fille du Prophète, de laquelle un sharīf descend nécessairement, soit par Ḥasan, soit par Ḥusayn. Durant les dernières années ou décennies, l'apparition des femmes dans les arbres généalogiques semble s'accentuer. Peut-être est-elle liée au fait que le nasab chérifien devient toujours histoire familiale (une famille d'ashräf en particulier), avec ses alliances matrimoniales et ses cousinages.

À cette volonté de narrer une histoire familiale où apparaissent les filles, voire les épouses, s'ajoute une particularité de la niqābat al-ashräf égyptienne. Si le nasab remonte de fils en père en grand-père etc. pour atteindre le Prophète, égrenant des chapelets de « fils de » (ibn), il peut aussi remonter de fils en mère en grand-père etc. (et l'on reprend le chapelet de fils de). Autrement dit, en Égypte, on peut être sharîf de mère comme de père, et la certification de la niqāba accepte que l'on soit sharîf de mère seulement. Lorsque, comme c'est souvent le cas, on est shariff par ses deux parents, on peut donc se faire établir, si nécessaire, deux arbres généalogiques, mais on ne possède toujours qu'une seule carte. Cette égalité de reconnaissance entre la transmission par le père ou par la mère est une singularité égyptienne, qui faisait déjà objet de débats à l'époque mamelouke et ottomane ${ }^{37}$. Elle est décriée par les Jordaniens qui n'imaginent pas un tel laxisme: pour eux, c'est la lignée paternelle seule qui compte pour définir l'identité et tracer la généalogie patrilinéaire, et n'est sharīf (ou sharīfa) que celui ou celle dont le père est sharīf. Quant aux Marocains,

Winter, "The Ashrāf and Niqābat al-Ashrāf", 19. 
réservés, ils voient dans la fantaisie égyptienne une déviance aberrante ayant cours également en Algérie : «c'est l'école de Tlemcen», me dit un généalogiste marocain avec quelque distance.

\subsection{Obstacles et enquêtes}

En général, une fois obtenu l'arbre généalogique initial, ou sa copie, et la preuve de son rattachement personnel à cet arbre familial, l'impétrant peut obtenir sa shahāda facilement, en un mois environ. Mais l'opération, bien souvent, n'est pas si simple, soit parce que l'impétrant n'a pas accès à l'arbre généalogique initial, ignore même s'il existe, où et chez qui, soit parce que cet arbre s'est perdu dans les hasards des migrations, des guerres, des révolutions.

Il est des cas de trous, parfois au sens littéral : l'arbre généalogique est abîmé, déchiré ou mangé aux vers, abîmé sur la pliure, comporte donc des trous, ou des noms devenus difficiles à déchiffrer: autant de chaînons manquants. Il peut enfin y avoir des lacunes dans la transmission entre l'impétrant d'aujourd'hui, l'arbre généalogique partiel qu'il arrive à reconstituer et la filiation prophétique, hasanite ou husaynite, dont il pense descendre et à laquelle il voudrait se rattacher. Le 1er février 2018, la doktora Huwayda 'Allām, une dentiste cairote en pantalon et tunique, d'origine turque précise-t-elle, un petit turban sur la tête, entre accompagnée par son mari dans la salle du Comité où tout le monde la connaît et l'appelle par son nom. Cela fait trois ans qu'elle multiplie les démarches et les recherches. C'est une descendante d'ashräf par son père (hasanite) et par sa mère (husaynite), qui elle-même descend d'un aïeul qui fut naqüb al-ashrāf à Simbillawayn, un gros bourg du Delta. Soit un membre de ces élites rurales, propriétaires terriens, qui furent en partie ruinés (mais pas tout à fait) par la réforme agraire. Huwayda a photocopié les pages du Baḥr al-ansāb qui mentionnent l'aïeul auquel remonte son arbre généalogique, et les a glissées dans son volumineux dossier ${ }^{38}$. Comment se fait-il qu'elle n'ait pu produire un arbre généalogique complet qui permette d'attester facilement de son origine ? Il y avait une interruption (inqița ) dans la transmission, m'explique un membre du comité, c'est-à-dire qu'il manquait des papiers et des preuves entre une génération et une autre.

38 Il s'agit du Baḥr al-ansāb d'al-Najafī, dont le titre complet est Kitāb bahr al-ansāb:aw al-Mushajjaral-kashshāfli-ușūl al-sāda al-ashrāf, al-mushtamil 'alā asmā'wa-ușūlwa-furū' wa-tawārīkh wa-manāqib wa-mazārāt wa-wafiyyāt 'umūm al-sāda al-ashrāffi kāffat biqāc al-arḍ li-Muhammad b. Aḥmad b. 'Amìd al-Dìn 'Al̄̄ al-Husaynī al-Najafì. 
Peut-être la rupture de la révolution de 1952 a-t-elle été fatale à létablissement des attestations nécessaires - les chaînons manquants entre Huwayda et son aïeul. Le père dominicain Josef Dreher, répétant les dires de témoins oculaires, m’a raconté qu'à la révolution nassérienne, des généalogies abandonnées par des grandes familles exilées ou en fuite jonchaient les trottoirs du Caire, étaient vendues au poids du papier par des chiffonniers. Sans doute Huwayda descend-elle d'une de ces familles de notables qui ont perdu leurs papiers, ou qui ont omis de faire enregistrer les naissances au sein de la famille. Ils doivent aujourd'hui renouer le fil de la famille et remplir les cases manquantes. Autre hypothèse : les brouilles familiales, les captations d'héritage, les mariages et remariages fragmentant l'héritage, dérobant les arbres, brouillant claire lignée, filiation et généalogie au hasard des ruptures et des procès.

Plus de trois ans de démarches et de patientes vérifications, en province et au Caire, ont permis à Huwayda, devenue généalogiste, d'accéder enfin à la shahāda tant espérée. Sa joie fait plaisir à voir, et chaque membre du Comité (depuis le temps, tout le monde la connaît par son nom) la félicite poliment. Elle m'explique en mots enthousiastes ce que représente cette quête : le lien avec le Prophète, bien sûr, mais aussi la certitude d'avoir reconstitué une partie de son histoire familiale et, désormais, de la connaître.

Tous n'ont pas cette chance. Nadia Naqïb, mon éditrice égyptienne dont le seul nom indique probablement une origine chérifienne, est Palestinienne. Comment prouver cette origine chérifienne quand tous les papiers de famille ont été perdus à jamais en 1948 ? Il ne reste du sharaf qu'une fama sanctitatis et une nostalgie de déracinés, et il faudrait déployer des efforts pendant des années - et comment enquêter en Israël pour un Palestinien exilé, 70 ans après la Nakba? - pour pouvoir produire au Comité les preuves tangibles du sharaf de la famille Naqīb. Nadia, qui vit au Caire, soupire en pensant à son père âgé, expulsé du Koweït en 1991 (encore des papiers perdus) et qui habite aujourd'hui Oxford: il serait si heureux d'obtenir la shahādat nasab pour renouer avec ses origines.

Supposons un autre cas, assez fréquent : le demandeur sait ou croit savoir à quel arbre il se rattache, mais ignore comment prouver de façon certaine son propre lien, lâche et collatéral, avec cet arbre, détenu par de lointains cousins qu'il ne connaît pas. C'est à lui de devenir généalogiste, de rechercher actes de mariage et certificats de naissance, dans un pays où l'état-civil existe depuis 1891 seulement ${ }^{39}$ et où, l'Égypte restant fidèle au nom en trois parties (ism thuläthī), le nom de famille n'existe pas, la plupart du temps. Plus exactement, il existe parfois des shuhra-s (noms d'usage), ou des nisba-s qui tiennent

“Décret concernant l'état-civil". 
finalement lieu de «noms de famille » dans les cas de ces familles confrériques comme, justement, les Qașabī, les Sharnūbī, les Sharīf d'Akhmim.

Quand bien même le demandeur arrive à produire ces papiers, il peut finalement exister des interpolations et des erreurs de noms, par exemple lorsque l'on emploie des surnoms (laqab) qui ne sont pas, pour autant, des noms de familles, ce qui prête à confusion des noms (le redoutable tashābuh asmä), ou des shuhra-s (noms d'usage) qui sont distinctes du nom inscrit sur les papiers, l'ism. Exemple: Galāl, un paysan en galabeyya, arrive au Comité. Le premier membre de la lajna auquel il tend ses papiers, homme d'expérience, pointe immédiatement la différence d'un nom - un seul, mais cela suffit pour poser problème - entre la généalogie alléguée (celle qui permettrait de prouver le sharaf) et celle que proposent les papiers d'identité. Galāl s'échauffe, donne des explications, souligne que chacun au village connaît cette double identité où la shuhra, le nom par lequel on est connu au village, est distincte du nom (ism) qui figure sur les papiers d'identité. On consulte le directeur administratif qui, prudent, renvoie l'affaire au directeur scientifique du Comité : lorsqu'il arrivera, il tranchera. Le paysan ressort dans la salle d'attente, maugréant, à moitié rassuré seulement. Ce flottement entre shuhra et ism est très fréquent en Égypte: le nom dont on se sert dans la vie courante n'est souvent pas celui des papiers administratifs. Un autre problème peut se poser: quand un nom de famille connu, une shuhra liée à un saint, est repris et donné comme nom à l'enfant d'un dévot ou d'un disciple, par baraka. Exemple : un Jīlānī ou Kīlānī peut être effectivement un descendant du saint ainsi nommé (le grand saint 'Abd al-Qādir al-Jīlānī, enterré à Bagdad) : ou bien il peut avoir été nommé ainsi par dévotion de ses parents au saint fondateur, sans qu'aucun lien généalogique ne l'y rattache; ou enfin, sans rapport avec le saint de Bagdad, il peut descendre de gens originaires du Gilan (le nord de l'Iran), comme Sīdī 'Abd al-Qādir lui-même. Passent les années, les décennies, les siècles : comment savoir si, dans une généalogie ou un recueil biographique, ce Jīlānī est un descendant, un disciple, un dévot ou un simple originaire?

Et les membres du Comité recopient et reconstituent toute la journée des généalogies dans de petits cahiers, à l'encre noire, en insérant dans les marges de petits commentaires en rouge, là où apparaît un problème à traiter.

\subsection{Dernière visite à la niqā $b a$ : 'Âtịf, sa mère, son grand-père et son saint ancêtre}

Terminons notre étude comme nous l'avons commencée, par la présentation d'un cas. Cette fois, il s'agit d'une dernière visite à la niqāba. Le mercredi 24 avril 2019, 'Āṭif se présente au Comité pour recueillir enfin les précieuses 
signatures. Quinquagénaire, en complet veston et cravate pour ce jour solennel, 'Ạțif appartient aux classes moyennes provinciales, de niveau plutôt élevé. 'Āṭif sait qu'il est sharîf de père et de mère, et possède tous les papiers nécessaires : il vient de la région de Mansoura, plus exactement du village de Barāmūn, situé au bord du Nil, sur la rive est, où sa famille maternelle est établie depuis des siècles. Sa famille paternelle était déjà une grande famille de la région de Mansoura à la fin du XVII ${ }^{\mathrm{e}}$ siècle. Pour 'Āṭif, contrairement à la doktora Huwayda ou au paysan Galāl dont le nom est connu au village, mais diffère de celui des papiers, l'affaire est simple, et c'est certain de son triomphe qu'il ne tarde pas à ouvrir son attaché-case rempli de pièces à conviction.

'Ạtịf est d'ailleurs un habitué de la niqāba: il a établi pour lui-même en 2016 une shahādat nasab d'après sa filiation paternelle, car son père, désormais décédé, était sharīf, hasanite, et descendant de Sīdī ‘Abd al-Salām b. Mashīsh (1140-1223). Ce célèbre saint marocain idrisside, enterré dans le Jabal 'Alam, près de Tétouan et de Ouezzane, fut l'initiateur d'Abū l-Ḥasan al-Shādhilī (m. 1258), et joua un rôle considérable dans l'histoire du soufisme. Aujourd'hui, 'Āṭif, fils dévoué, vient faire établir la shahādat nasab de sa mère veuve, sharīfa également, mais issue d'une tout autre branche, et husaynite. Née en 1936, elle est sans doute trop âgée pour se déplacer au Caire et faire les démarches, d'autant qu'elle appartient à une génération où, à la différence de la dentiste Huwayda, les femmes restaient à la maison. Mais 'Ạṭif a constitué le dossier, produit les pièces justificatives, et a rempli pour sa mère les rubriques suivantes sur la page de couverture du dossier vert, soigneusement numéroté par la niqāba:

- nom (Fāṭima al-Sayyid 'Alī Aḥmad 'Ashīsh),

- lieu d'habitation (al-Barāmūn, district de Mansoura, gouvernorat de la Daqahliyya),

- nationalité (égyptienne),

- nom de famille (shuhrat al-usra : 'Ashīsh),

- branche de la généalogie chérifienne liée à la généalogie de la famille ( $\mathrm{far}^{\mathrm{c}}$ al-nasab al-sharîf alladhìyattașilu bi-nasab al-usra: dans son cas, la réponse est al-Ḥusayn),

- adresse où envoyer une correspondance (la réponse indique simplement le nom du village), un numéro de téléphone,

- renseignements complémentaires; documents exigés par le Comité (al-mustanadāt wa-l-istifsārāt al-mațlūba li-l-lajna) : la case est restée vide,

- résultat de la recherche du Comité (natijat bahth al-lajna) qui ne peut être qu'acceptation (qubūl al-țalab wa-taharrur bițāqat nasab raqm ...) ou refus motivé (rafḍal-țalab bi-sabab ...). L'espace est encore vide, mais les membres du comité vont signer dans un instant, et 'Āṭf tremble d'émotion en brandissant les papiers sous le nez du docteur Sulaymān. 
À l'intérieur du dossier est agrafée une feuille avec la photographie d'identité de l'impétrante. Il s'agit d'un formulaire sous forme de lettre adressée au naqīb, qui demande des renseignements complémentaires:

- nom,

- [originaire] de la famille (min usra),

- Lieu actuel (al-mawțin al-ḥālì, elle répond al-Barāmūn),

- lieu d'origine (al-mawțin al-aṣlī, elle répond de même),

- travail ('amal: réponse rabbat al-bayt, maîtresse de maison),

- coordonnées de la pièce d'identité, éventuellement du passeport,

- nationalité (égyptienne),

- noms des fils et des filles (huit cases sont prévues, mais il a fallu en rajouter une à la main, car Fāțima a eu neuf enfants, quatre fils et cinq filles),

- Le formulaire précise pour finir que l'attestation de généalogie (bițāqat nasab) est une carte de sharaf (littéralement: « d'honneur ») (bițāqa sharafiyya), et qu'il est obligatoire de ne pas avoir été jugé pour crime ou meurtre. Il s'achève par la signature de l'impétrante.

$\mathrm{Au}$ bout d'un mois, les démarches de 'Āṭif pour sa mère sont sur le point d'aboutir, et ce mercredi où il va obtenir les signatures des membres du Comité est pour lui un jour faste. Dès son arrivée, il déploie l'arbre généalogique de sa famille maternelle auprès du docteur Sulaymān, auquel il confie une photocopie de l'arbre, qui restera dans les archives de la niqāaba. L'original (la rolla) a été très manipulé, mais reste lisible : le document daté de Ramadan 1120 de l'hégire (1708-9), comprend un rajout daté de 1215 de l'hégire (1800-1801). Les deux textes ottomans furent alors authentifiés par les signatures de quatre témoins, à Mansoura, dont l'imam de la grande mosquée et le naqüb al-ashräf de Mansoura. Sur le parchemin que tient fièrement 'Ātifi, les quatre lignes du nasab qui ont trait aux 'Ashāyish ont été - horresco referens - surlignées au stabilo jaune. Il s'agit d'un passage important, qui interrompt la généalogie pour donner les noms de trois frères et de leurs cousins paternels, dire leur installation à al-Barāmūn (le manuscrit écrit : Barāmūn) et narrer leur constitution en une famille, les 'Ashīsh ou Ashāyisha, tous descendants du saint le cheikh al-Sayyid 'Abd al-Raḥman 'Ashīsh. On assiste à la constitution d'une famille «qui compte », à cause du saint ancêtre, à cause de la propriété terrienne, à cause d'un ancrage local ancien. Toutes choses qui sont liées à son origine chérifienne: toutes choses que vient confirmer, en fait, le sharaf.

Solidement appuyée sur son arbre généalogique ottoman, au XIX ${ }^{\mathrm{e}}$ siècle, la famille 'Ashīsh vient occuper le devant de la scène, au point que la copie d'un arbre généalogique «à l'européenne » (avec les ramifications dessinées sur le papier, et non une seule liste de noms) restreint de la famille a été jointe au dossier. Cet arbre est à la fois raccourci (il ne remonte pas jusqu'au Prophète, mais seulement jusqu'au saint ancêtre des 'Ashīsh, devenu le 'amūd al-nasab) 
et élargi (on prend en compte tous les descendants, filles et garçons, du saint ancêtre). Il a été dressé sur une feuille en 1968 - précisément par al-Sayyid 'Alī (né en 1898), le grand-père de 'Ātif, le propre père de Fāțima qui, cinq générations après le saint fondateur, figure sur l'arbre aux côtés d'innombrables cousins $^{40}$. Si les épouses n'y figurent pas, les filles sont mentionnées, de même que la mention sans descendance et même, pour une sœur d'al-Sayyid 'Alì : ne s'est pas mariée. Il ne s'agit là ni d'une généalogie patrilinéaire, ni d'une suite linéaire, mais d'un arbre complexe, avec les cousins et les alliés. Pour l'origine, après la basmala, tout en haut de l'arbre, on ne remonte pas au Prophète, ni même à 'Alī et Fāṭima, à Ḥasan ou Ḥusayn, mais - et cela suffit - au saint ancêtre le saint et le pieux (al-walī al-șălih) al-Sayyid 'Abd al-Rahman 'Ashīsh. Son nom est encadré par deux formules: «Dieu maudit qui entre chez nous sans nasab» (la'ana Llāh al-dākhil finā min ghayr nasab) et à gauche «car, parmi les plus grands mensonges, est celui de l'homme qui se réclame d'un autre père que le sien » (inna min a'zam al-firā an yadda ciya l-rajul ilā ghayr abīhi). $\mathrm{Au}$ bas de la page, dans sa longue signature, le grand-père de 'Ạṭif se présente à la fois comme cheikh soufi, comme écrivain et comme ouléma (katabahā al-faqür ilä Llāh al-kätib wa-l-faqī al-shaykh al-sayyid 'Alì Aḥmad 'Ashìsh), ajoute la date mīlādì, suivi de la date hégirienne, et finalement un titre: arbre des ashraf'Ashayish de Barāmūn (mushajjar nasab al-sāda al-ashrāf al-'ashāyisha bi-l-Barāmūn, al-Manșūra, al-Daqahliyya). En 1968, à une époque où la niqāba avait disparu, où plus personne ne pouvait certifier la chérifienne ascendance de ses petits-enfants et de ses nombreux cousins, le sayyid 'Alī 'Ashīsh avait fourni pour plus tard un précieux document, agrafé aujourd'hui dans le dossier de sa dernière fille, Fāṭima, par les soins de son petit-fils 'Āṭif. Celui-ci a également agrafé le contrat de mariage de ce grand-père, qui se maria en 1915 à Barāmūn selon le rite hanafite (encore une preuve de l'importance de l'époque ottomane pour ces élites des ashräf). Produire la copie de ce contrat de mariage n'ajoute rien aux preuves du sharaf, mais ce document signé par l'arrière-grand-père maternel et l'arrière-grand-oncle maternel de 'Āṭif, estampillé des sceaux et des tampons nécessaires, est une preuve supplémentaire de l'importance sociale des 'Ashāyish à Baramūn. Le sharaf va de pair avec une forme de noblesse.

Exultant, ému, 'Āṭif repart avec le certificat de nasab de sa mère, dûment authentifié par les signatures des membres du Comité. De son côté, le Comité a fait une bonne affaire, car le dossier de 'Āṭif va s'ajouter aux centaines de dossiers traités et archivés chaque année : une nouvelle histoire, de nouveaux

40 Cet espace de cinq générations laisse supposer une fourchette temporelle qui peut aller de 100 à 150 ans. Le saint fondateur de la famille 'Ashīsh aurait donc vécu au XVIII ${ }^{\mathrm{e}}$ siècle. 
noms, de nouveaux échelons - génération après génération - un nouvel éclairage sur une région d'Égypte. C'est avec ce matériel que la niqāba fait établir des documents récapitulatifs constamment mis à jour, dont le Comité se sert pour son travail, comme une sorte d'index des «grandes familles» d'ashrä $f$ égyptiens, établi en 2018 dans de grands classeurs, par ordre alphabétique des nisba-s $\mathrm{s}^{41}$.

Pour finir, le dossier de 'Āṭif présente des caractéristiques que l'on retrouve sans cesse dans les dossiers traités par la niqāba: soufisme, ancrage provincial, territoire, terre, notabilité, famille. Il ne s'agissait pas tant de prouver que la mère de 'Āṭif descendait du Prophète (tout al-Barāmūn sait l'origine des 'Ashīsh), mais, par le fait même d'établir le certificat, de faire acte de piété filiale envers une mère âgée, de perpétuer à son tour la longue mémoire d'une sainte famille, de son ancrage local à Barāmūn, du souvenir des hommes et femmes de sa famille - y compris celui qui n'a pas engendré, celle qui n’a pas enfanté, et celle qui ne s'est pas mariée. C'était aussi prouver la notabilité d'une famille en un lieu : voilà ce que signifie, pour 'Ātịf, descendre du Prophète. Après les lointains témoins du XVIII ${ }^{\mathrm{e}}$ siècle et à la suite de son grand-père en 1968, 'Āṭif à son tour aura fait œuvre pie dans la transmission d'une mémoire et d'un nasab. Nous continuerons à ignorer pourquoi, fils cadet, il aura joué ce rôle au lieu et place de son frère aîné, devenant ainsi, et jusqu’à sa mort, le kabìr al- ẩila : celui qui maîtrise la généalogie et l'histoire de sa famille, celui qui fait le lien avec la niqābat al-ashrāf.

\subsection{Conclusion}

La niqāba égyptienne se veut unique au monde : c'est la seule niqāba, me dit fièrement le docteur Sulaymān, qui soit à la fois «administration, sanctuaire, bâtiment et dotée de fonctionnaires » (idāra, haykal, mabnā, muwazzafin). Du point de vue de l'État égyptien, cette importance et cette centralité font partie d'un héritage multiséculaire que la construction de l'État khédivial, monarchique et même républicain n’a fait que renforcer. C'est ce qui explique que l'Égypte puisse prodiguer des certificats de sharaf selon ses procédures bureaucratiques, méthodiques, et d'après ses archives propres. Et c'est à partir de ce centre que, me disent les gens du Comité, l'on peut échanger des informations pour reconstituer des généalogies, avec d'autres États concernés par la question des ashräf, comme l'Irak, la Jordanie, le Maroc, l'Arabie saoudite et

41 J'ouvre au hasard un classeur et tombe sur la famille Zabīdī, descendante de Murtaḍā al-Zabīdì (m. 1791). 
même l'Indonésie. Même si chaque pays a son système (nizām), comme me le dit prudemment Aḥmad Yahyā, «l'Égypte est seule à examiner les arbres », me dit-on fièrement au Comité, la seule à décider non seulement de l'authenticité, mais de savoir s'il s'agit de la branche husaynite ou hasanite.

Ces démarches complexes, parfois coûteuses, et qui ne rapportent rien - à peine un vague prestige, de plus en plus ignoré ou suspecté par les salafistes maintiennent la conscience de soi des ashräf, plus exactement de ceux pour lesquels il importe encore, toujours, de préserver les arbres, de faire établir la shahāda, d'avoir la carte: «Nous sommes une famille», conclut Ahmad Yahyā. Les ahl al-bayt, Ḥasan et Ḥusayn, mais aussi Sayyida Zaynab, les quatre $a q t a \bar{b} b$ qui étendent leur ombre sur le soufisme égyptien, les saints d'Égypte toujours vénérés, le 'amūd al-nasab qui a donné un nom à une famille, le maillage quasi-paroissial de terroir, qui seul permet de reconstituer l'histoire d'une famille, les souvenirs d'ancêtres fortunés qui vécurent ici ou là, voici un siècle, ou deux, ou trois : ce sont toutes ces strates, ces étapes, ces niveaux différents de référence et de mémoire qui sont éveillés chaque fois qu'apparaît un arbre généalogique à la niqāba. Chaque étape, chaque lien, chaque preuve apportée à la niqāba - y compris les preuves inutiles - est une sorte de manifestation de la présence du Prophète hier et aujourd'hui dans ses descendants. C'est un lien toujours recréé, toujours réécrit, et qui, une fois incorporé, doit se manifester dans les qualités spécifiques que les ashräf doivent incarner, selon les membres de la niqāba. À la fin, la patiente enquête de vérification du nasab redit l'histoire - tout ce temps, ces chaînons et ces étapes qui séparent les ashrāf du Prophète - et permet aussi d'en sortir - le Prophète est toujours proche, toujours présent dans ceux de ses descendants qui choisissent de l'être.

\subsection{Annexe : Liste des naqübs de la niqābat al-ashräf de l'Égypte contemporaine}

Muḥammad Abū Hādī al-Sādāt

Aḥmad b. Ismācill al-Sādāt

Muhammad b. 'Abd al-Mun'im al-Bakrī

Aḥmad b. Muhammad al-Bakrī

Muhammad al-Bakrī al-Kabīr

Muhammad al-Bakrī al-Ṣaghīr

'Umar Makram Ḥusayn al-Asyūṭī

Muḥammad Wafā 'Abd al-Ḥamīd al-Sādāt

Muḥammad Aḥmad Muḥammad al-Dawākhilī
?-1168/1754-55
$1168 / 1754-55^{-1176 / 1762-63}$
$1176 / 1762-63-?$
?-1195/1781
$1195 / 1781-1196 / 1782$
$1196 / 1782-1208 / 1793$
$1208 / 1792-1224 / 18 \circ 9$
$1224 / 18 \circ 9-1228 / 1813$
$1228 / 1813-1231 / 1816$ 
(cont.)

Muhammad Muhammad Abū l-Su'ūd al-Bakrī

'Alī Muhammad Muhammad al-Bakrī

'Abd al-Bāqī 'Alī Muḥammad al-Bakrī

Muhammad Tawfìq 'Alī Muhammad al-Bakrī

1231/1816-1271/1854
1271/1854-1297/1879
1297/1879-1309/1891
1309/1891-1312/1895
Second mandat 1903-11 (ce
second mandat est occulté
de la généalogie officielle
qui se poursuit comme
ci-dessous)
1312/1895-1323/1905
1323/1905-1373/1953
1411/1991-1415/1994
1415/1994-1429/2008
$1429 / 2008-$

$1231 / 1816-1271 / 1854$

$1271 / 1854-1297 / 1879$

(1297/1879-1309/1891

1309/1891-1312/1895

second mandat est occulté

de la généalogie officielle

qui se poursuit comme

ci-dessous) ${ }^{42}$

'Alī Muḥammad Aḥmad al-Biblāwī

Muḥammad 'Alī Muḥammad al-Biblāwī

Maḥmūd Aḥmad Kāmil Yāsīn al-Rifāēì

Aḥmad Aḥmad Kāmil Yāsīn al-Rifācī

al-Sayyid Mạ̣mūd al-Sharīf

(1)

\section{Bibliography}

\section{Primary Sources}

Bakrī, M. T. Bayt al-sādāt al-wafä̀iyya, Cairo, n.d.

Bakrī, M. T. Bayt al-Ṣiddīq, Cairo, Mațba'at al-Mu’ayyad, 1905.

Biblāwī, M. 'A. al-Ta'rīf bi-l-nabì wa-l-qur'ān al-sharīf, Cairo, Maṭba'at Dār al-Kutub al-Mișriyya, 1927.

Biblāwī, M. 'A. Tārīkh al-hijra wa-bad' al-islām, Cairo, Mațba'at al-I'timād, 1927.

Khafājī, M., et 'A. Șuḅ̣. al-Azhar fì alf 'ām, 3 vols, Cairo, al-Maktaba al-Azhariyya li-l-Turāth, 2012.

Najafī, M. Baḥr al-ansāb, ed. Ḥ. M. al-Rifāīè, Cairo, Dār al-Kutub wa-l-Wathāìq al-Markaziyya, 2006.

\section{Secondary Literature}

Abu-Zahra, N. The Pure and Powerful: Studies in Contemporary Muslim Society, London, Ithaca Press, 1997 ; 2 e édition révisée en 2000.

Ammar, H. Growing Up in an Egyptian Village, London, Routledge and Kegan Paul, 1954.

42 Je remercie vivement Adam Mestyan pour sa lecture et pour avoir attiré mon attention sur ce second mandat occulté, à cause de la maladie mentale du cheikh Tawfĩq al-Bakrī et de ses écrits controversés. 
Berque, J. Histoire sociale d'un village égyptien, Paris-La Haye, Mouton, 1957.

Biegman, N. H. Moulids, Saints, Sufis : Egypt, London, Gary Schwartz and Kegan Paul, 1990.

Botiveau, B. "L'université al-Azhar au gré du changement politique", in H. Bleuchot, ed., Les institutions traditionnelles dans le monde arabe, Paris, Karthala-IREMAM, 1996, 211-28. En ligne : https://books.openedition.org/iremam/278?lang=fr.

Charbel, J. "Egypt's Oldest Surviving Syndicate", Egypt Independant, 23 janvier 2010, www.egyptindependant.com.

Chih, R. Le soufisme au quotidien. Confréries d'Égypte au XX $X^{e}$ siècle, Paris, Sindbad-Actes sud, 2000.

Chih, R. Sufism in Ottoman Egypt: Circulation, Renewal and Authority in the Seventeenth and Eighteenth Centuries, Abingdon, Routledge, 2019.

"Décret concernant l'état-civil", Documents diplomatiques, Affaires d'Égypte 1884-1893, Paris, Imprimerie nationale, 1893, 395-401.

De Jong, F. Turuq and Țuruq-linked Institutions in Nineteenth-Century Egypt : A Historical Study in Organizational Dimensions of Islamic Mysticism, Leiden, Brill, 1978.

Delanoue, G. Moralistes et politiques musulmans dans l'Égypte du XIX siècle, Cairo, IFAO, 1983 .

Falk Gesink, I. Islamic Reform and Conservatism : Al-Azhar and the Evolution of Modern Sunni Islam, London, I.B. Tauris, 2014.

Gilsenan, M. Saint and Sufi in Modern Egypt, Oxford, Clarendon Press, 1973.

Grangaud, I., et N. Michel, eds. L'identification. Des origines de l'islam au XIX'e siècle, Revue des mondes musulmans et de la Méditerranée 127 (2010).

Jordan, D. "The Rifāiyya in 2oth-Century Iraq: Țhe Role of Sufi Genealogies and Veneration of Saints in Iraqi Political History", Thèse doct., University of Hamburg, 2019 .

Jungen, C., ed. L'ethnologue et les archives, Ateliers d'anthropologie 32 (2008).

Jungen, C., et C. Raymond, eds. Pratiques d'archives. Fabriques, modelages, manipulations, Ateliers d'anthropologie 36 (2012).

Luizard, P.-J. "Al-Azhar, institution sunnite réformée", in A. Roussillon, ed., Entre réforme sociale et mouvement national, Cairo, CEDEJ (1990), 519-48.

Luizard, P.-J. "Le soufisme égyptien contemporain", Médiateurs et métaphores, Égypte-monde arabe (1990), 35-94.

Mayeur-Jaouen, C. Histoire d'un pèlerinage légendaire en islam. Le mouled de Tantâ du XIII ${ }^{e}$ siècle à nos jours, Paris, Aubier-Flammarion, 2004.

Mayeur-Jaouen, C. Pèlerinages d'Égypte, Paris, Éditions de l'EHEss, 2005.

Mayeur-Jaouen, C. "Nasab, Baraka and Land: Hagiographic and Family Memory Entwined in the Egyptian Brotherhood of Sharnūbiyya, from the Fourteenth Century until Today", in A. Papas et C. Mayeur-Jaouen, eds, Family Portraits with 
Saints : Hagiography, Sanctity, and Family in the Muslim World, Berlin, Klaus Schwarz Verlag, 2014, 159-97.

Mayeur-Jaouen, C. "The Small World of Ahmmad al-Ṣāwī (1761-1825), an Egyptian Khalwatī Shaykh", in M. Kemper et R. Elger, eds, The Piety of Learning: Islamic Studies in Honor of Stefan Reichmuth, Leiden, Brill, 2017, 105-44.

McGregor, R. Sanctity and Mysticism in Medieval Egypt: The Wafa Sufi Order and the Legacy of Ibn Arabi, New York, SUNY, 2004.

Mestyan, A. "al-Bakrī, Muḥammad Tawfīq", in K. Fleet et al., eds, Encyclopaedia of Islam, Third Edition, Leiden, Brill, 2019.

Mughazy M. et A. Sabra (ed. et introd.), The Merits of the Bakrī Lords. An Anthology/ Manāqib al-Sāda al-Bakriyya, Beyrouth, Dār al-Machreq, 2015.

Oualdi, M., et N. Amara, eds. La nationalité dans le monde arabe des années 1830 aux années 1960, Revue des mondes musulmans et de la Méditerranée 137 (2015).

Paonessa, C. "Le rôle des confréries soufies durant les élections législatives de 2011 en Égypte : quelques réflexions préliminaires", Égypte Monde Arabe 10 (2013), 129-152.

Peskes, E. al-Aidarus und seine Erben. Eine Untersuchung zu Geschichte und Sufismus einer hadramitischen Sada-Gruppe vom fünfzehnten bis zum achtzehnten Jahrhundert, Stuttgart, Franz Steiner, 2005.

Raineau, T. "Des tableaux noirs à l'ombre du minbar. La réforme de l'université d'al-Azhar (1895-1913)", Islam et éducation au temps des réformes, Cahiers de la Méditerranée 75 (2007), 9o-104.

Raineau, T. "Mendiante et orgueilleuse ? Luniversité d'al-Azhar et l'enseignement supérieur égyptien (1860-1930)", Enseignement supérieur, pouvoirs et mondialisation dans le monde arabe, Revue des mondes musulmans et de la Méditerranée 131 (2012), 111-26.

Sabra, A. "Household Sufism in Sixteenth-Century Egypt: The Rise of al-Sāda al-Bakriyya", in R. Chih et C. Mayeur-Jaouen, eds, Le soufisme à l'époque ottomane, Sufism in the Ottoman Era, Cairo, IFAO, 2010, 101-18.

Sedgwick, M. Saints and Sons: The Making and Remaking of the Rashidi Ahmadi Sufi order (1799-2000), Leiden, Brill, 2005.

Skovgaard-Petersen, J. Defining Islam for the Egyptian State: Muftis and Fatwâs of the Dâr al-Iftâ', Leiden, Brill, 1997.

Winter, M. "The Ashrāf and Niqābat al-Ashrāf in Egypt in Ottoman and Modern Times", Asian and African Studies 19 (mars 1985), 17-41.

Winter, M. "The Ashrāf and the Naqīb al-Ashrāf in Ottoman Egypt and Syria: A Comparative Analysis", in K. Morimoto, ed., Sayyids and Sharifs in Muslim Societies : The Living Links to the Prophet, London/New York, Routledge, 2012, 139-57. 